\title{
Conceptos científicos y sentido común: una aproximación pragmatista a la ontosemántica estructural ${ }^{*}$
}

Scientific Concepts and Common Sense: A Pragmatist Approach to Structuralist

Ontosemantics

José Luis Liñán $n^{\dagger \ddagger}$

\begin{abstract}
Resumen
En este trabajo defiendo que la relación entre los conceptos científicos y las habilidades conceptuales de sentido común no es modelo-teórica, y por lo tanto no puede reconstruirse a partir de la noción técnica de 'vínculo interteórico'. Los conceptos ordinarios ofrecen las condiciones prácticas de acceso al aparato conceptual de las teorías científicas: la relación global entre ambos niveles es de dependencia pragmática, con transiciones locales dinámicas. Esta revisión de la (onto-)semántica estructuralista contribuye a aclarar la cuestión de la inconmensurabilidad y deshace el dilema epistemológico entre fundamentismo y coherentismo.
\end{abstract}

Palabras clave: inconmensurabilidad - inferencialismo - vínculos interteóricos - fundamentismo - coherentismo

\begin{abstract}
In this paper I argue that the relationship between scientific concepts and common-sense conceptual capabilities is not model-theoretical, and thus cannot be reconstructed on the technical concept of 'inter-theoretical link'. Ordinary concepts provide practical access conditions to the conceptual apparatus of scientific theories: the global relation between both levels is best described in terms of pragmatic dependence, with local dynamic transitions. This pragmatic revision of structuralist (onto-)semantics sheds light on the issue of incommensurability and helps to dissolve the epistemological dilemma between foundationalism and coherentism.
\end{abstract}

Keywords: incommensurability - inferentialism - intertheoretical links - foundationalism - coherentism

\footnotetext{
* Recibido: 20 de septiembre de 2012. Aceptado con revisiones: 11 de enero de 2013.

† Facultad de Filosofía, Pontificia Universidad Católica de Chile, Chile. Para contactar al autor, por favor, escribir a: jolinan@uc.cl.

* Este trabajo se benefició del proyecto de investigación Fondecyt 3150414 (Conicyt, Gobierno de Chile). Metatheoria 57-84. ISSN 1853-2322. eISSN 1853-2330.

(c) Editorial de la Universidad Nacional de Tres de Febrero. Publicado en la República Argentina.
} 


\section{Introducción}

Como toda empresa intelectual, la reconstrucción metateórica de teorías científicas puede contemplarse como persiguiendo diversos fines. El más inmediato es la elucidación de la estructura lógico-conceptual de las teorías científicas, tanto en los casos particulares de teorías o disciplinas específicas, como en lo que se refiere a aspectos generales o comunes a todas las teorías consideradas empíricas. Este objetivo se vincula al interés tradicional de la epistemología, primero, y la filosofía de la ciencia, después, por las formas de representación de los que nos servimos para conocer la realidad y de las que en particular se sirven nuestras teorías científicas -incluidas las (meta)teorías, que aspiran a reflejar la estructura de otras teorías-, interés que algunos autores han estimado como el único que en primera instancia compete a la filosofía cuando ésta se libra de ciertas pretensiones que cabría llamar "metafísicas", en el sentido peyorativo señalado por el positivismo lógico.

Otros objetivos intermitentemente reivindicados por la reciente filosofía de la ciencia rebasan sin embargo el ámbito puramente formal de los medios de representación para invadir de lleno cuestiones que por contraste podemos calificar como materiales, y que se refieren a la naturaleza de aquellos sectores de la realidad que las teorías científicas reconstruidas pretenden explicar. Una de las razones que motivan la reconstrucción de teorías científicas es la de averiguar qué entidades afirman éstas que hay, y cómo acceden dichas teorías a semejantes conclusiones. Suele entenderse que la elucidación e interpretación lógica de las teorías científicas pone al descubierto determinadas clases de entidades con cuya existencia las teorías en cuestión supuestamente están comprometidas, en la medida en que aspiran a subsumir bajo su aparato explicativo sistemas concebidos a partir de tales clases básicas. Así pues, después de todo, la reconstrucción metateórica recupera en algún sentido las cuestiones ontológicas o metafísicas que tradicionalmente han venido formando parte de las inquietudes generales de la filosofía.

El estructuralismo metateórico se presenta como una propuesta de análisis global de la ciencia, y por lo tanto se topa de manera natural con las polémicas clásicas relativas a estas cuestiones generales. Al menos desde Frege se acepta que para responder adecuadamente a estas cuestiones, se necesita primero elucidar cuál es la semántica -y, a partir del segundo Wittgenstein, la pragmática- de nuestro lenguaje en general, y la de las teorías científicas en particular. En varios de sus escritos, Carlos Ulises Moulines defiende la competencia del estructuralismo para acometer esta, digamos, "cuestión del ser" en toda su profundidad y generalidad, y expone el tipo de respuesta que podríamos esperar obtener a partir de los instrumentos estructuralistas de análisis y reconstrucción de las ciencias. ${ }^{1}$ Esta empresa ha recibido el nombre de "ontosemántica" o, de forma más completa, "ontoepistemosemántica" de las teorías científicas.

En uno de los primeros trabajos en los que avanza los rudimentos de este proyecto, Moulines (1987) conecta expresamente la vocación ontológica de la reconstrucción metateórica con el problema, destacado por Kuhn, de la inconmensurabilidad de las teorías científicas. El estructuralismo concibe la inconmensurabilidad entre pares de conceptos de dos teorías remitiendo la determinación del contenido de éstos a teorías subyacentes, que estarían a la base de ambas. Este procedimiento incoa un rastreo "genealógico", por decirlo así, del significado de los términos científicos. El problema es que, en virtud del criterio de teoricidad que canónicamente ofrece el estructuralismo, esta búsqueda de teorías cada vez más básicas desemboca e la siguiente alternativa epistemológica: o bien nos acabamos topando con una o más teorías que servirían de fundamento a todas las demás pero cuyos conceptos serían todos teóricos, o bien aceptamos un coherentismo por el cual la totalidad de la ciencia se autojustificaría (ver Balzer, Moulines \& Sneed 1987, cap. VIII, sec. 6). Cualquiera de estas posibilidades se revela problemática a la luz misma de las pretensiones del programa ontosemántico,

\footnotetext{
${ }^{1}$ Ver, por ejemplo, Moulines (1987, 1991, 1998, 2012).
} 
especialmente porque esta circunstancia siembra dudas acerca de la capacidad del estructuralismo para dar cuenta de la intuición general según la cual las teorías científicas reciben apoyo de la experiencia.

Mi objetivo en este trabajo es cuestionar algunos fundamentos del proyecto ontosemántico tal y como queda recogido y planteado en escritos de la corriente estructuralista. No haré por ello ninguna objeción a los procedimientos técnicos de análisis y reconstrucción estructuralista, sino sólo al modo en el que estas técnicas se interpretan filosóficamente a la hora de formular algo así como una empresa ontosemántica. La dificultad estriba a mi parecer en una inadecuada concepción de la semántica y, en particular, una deficiente comprensión de los sistemas conceptuales, en el bien entendido de que las teorías científicas son una clase de sistemas conceptuales especialmente rígidos y con ciertas características adicionales. Uno de los aspectos de dicha concepción que pretendo poner en duda concierne a la relación de los conceptos con la experiencia, y por lo tanto involucra de lleno consideraciones epistemológicas. ${ }^{2}$ Encuentro que algunas interpretaciones de criterio de teoricidad estructuralista permanecen aferradas a un enfoque positivista de la relación evidencial de las teorías con la empiria, en un sentido que espero aclarar más adelante. Considero que algunos autores han sido conscientes de estas insuficiencias, y han tratado de resolverlas, ya mediante una teoría de individuación de los conceptos científicos que respetara las bases del programa original (Díez 2002), ya a través de una reconsideración inferencialista de los sistemas conceptuales (Zamora Bonilla 2003). Mi propia posición se encuadra dentro de este último enfoque.

Sostengo que el inferencialismo semántico inspirado en Sellars y desarrollado en los últimos años por Robert Brandom (1994, 2000a, 2008) ofrece herramientas teóricas que evidencian las raíces representacionalistas de la interpretación que muchos autores estructuralistas hacen de la empresa ontosemántica. Me parece que el representacionalismo es una teoría equivocada acerca de cómo se relacionan nuestros conceptos con la realidad o, dicho de otro modo, nuestras teorías con la experiencia. No trataré de argumentar a favor del inferencialismo de modo independiente; espero mostrar, sin embargo, que el inferencialismo arroja una semántica de los conceptos que responde a las restricciones pragmáticas que penden sobre ellos, y que al responder de este modo a la pragmática proporciona una visión más plausible de en qué consiste la capacidad de nuestras teorías para representar el mundo.

\section{Inconmensurabilidad}

Un problema con relación al cual se suele señalar la capacidad de la reconstrucción estructural para esclarecer los ámbitos de aplicación de las teorías científicas es el llamado problema de la inconmensurabilidad de las teorías. Aunque el tema es bien conocido, comenzaré esta sección recordando brevemente sus aspectos centrales. A continuación, pasaré a considerar la interpretación del mismo que ofrece el estructuralismo.

El problema de la inconmensurabilidad de las teorías científicas cobra relieve a partir de la publicación, en 1962, de The Structure of Scientific Revolutions. En dicha obra, Thomas S. Kuhn ofrece una imagen de la ciencia que rivaliza con los enfoques metodológicos anteriores, por cuanto presta una atención destacada a la historia de la ciencia con el objeto de extraer conclusiones acerca de la naturaleza misma del conocimiento científico. Según Kuhn, la historia de la ciencia es una sucesión de periodos de ciencia normal y de periodos de ciencia revolucionaria. Durante los periodos de ciencia normal, la actividad predominante es la resolución de problemas y la consiguiente acumulación de conocimientos dentro de un marco teórico que no se discute de manera global. Las revoluciones científicas constituyen hiatos o saltos entre dos periodos de ciencia normal, y se caracterizan por un cuestionamiento radical del marco teórico anterior. Si la revolución científica triunfa, el viejo marco

\footnotetext{
2 Por eso, aunque para abreviar he escrito y seguiré escribiendo “ontosemántica”, me referiré con ello a la más completa forma “ontoepistemosemántica” -o incluso “ontoepistemosemánticopragmática”, como contempla Moulines (2012).
} 
teórico $T$ es suplantada por uno nuevo, $T^{*} \cdot{ }^{3}$ El marco teórico resultante de una revolución científica será eventualmente inconmensurable con respecto al marco teórico precedente. Lo interesante del caso es que, aunque $T$ y $T^{*}$ son inconmensurables, son comparables en algún sentido; en particular, se reconoce que pretenden ocuparse de lo mismo (los mismos hechos o el mismo dominio empírico). De lo contrario, la inconmensurabilidad sería trivial e irrelevante.

En sus primeros escritos, y especialmente en The Structure of Scientific Revolutions, Kuhn entendió que la inconmensurabilidad cubría un amplio espectro de fenómenos en los que la discrepancia entre las teorías en cuestión se manifestaba: cambios perceptivos (gestálticos), intraducibilidad, disparidades conceptuales y metodológicas. Posteriormente, Kuhn prefirió centrarse en los aspectos lingüísticos o categoriales, concibiendo la inconmensurabilidad como una incompatibilidad local de taxonomías léxicas (estructuras taxonómicas) o "esquemas conceptuales": dos teorías (o marcos teóricos) inconmensurables poseen vocabularios clasificatorios incompatibles, por lo que "trocean" de manera diferente la realidad. ${ }^{4}$ Una variación semántico-conceptual revierte en una inconmensurabilidad ontológica, a través de una divergencia referencial en lo que respecta a los términos involucrados. Se ha defendido que a los planteamientos kuhnianos subyace un presupuesto nominalista, de acuerdo con el cual la realidad consta de entidades individuales independientes del sujeto, que no vienen clasificadas o troceadas en clases naturales. ${ }^{5}$ Es cada una de las teorías rivales la que opera la partición, de modo que cualquier intento de integrar ambos enfoques producirá por fuerza solapamientos taxonómicos.

De acuerdo con la última caracterización de Kuhn, intuitivamente, dos teorías son inconmensurables cuando no existe una unidad de medida común que permita: (a) establecer correlaciones sistemáticas entre los conceptos y las leyes de ambas teorías; (b) estipular criterios de evaluación que determinen cuál de las dos teorías es cognitivamente más progresiva. Si recordamos que, en los casos interesantes, ambas teorías han de ser también en algún sentido comparables, la cuestión que inmediatamente se plantea es la siguiente: ¿Por medio de qué recursos podemos establecer la comunidad de comparación entre las dos teorías inconmensurables? ¿Puede identificarse la parte de la realidad a la que las dos teorías pretenden aplicarse con independencia de ambas? Necesitamos algún medio de precisar cuál es la base empírica común de la que se ocupan dos teorías inconmensurables, y en qué reside entonces el aspecto específico de inconmensurabilidad. Incluso si no asumimos el presupuesto nominalista anterior, parece claro que el problema no se resuelve de manera directa, por ejemplo observando, con "mirada inocente" y al margen de cualquier enfoque teórico, el sector de realidad al que ambas teorías se dirigen, para a continuación decidir cuál de las dos responde mejor a la realidad de los hechos. Se impone por ello aclarar en qué medida el estructuralismo puede proporcionar un marco metateórico, y por lo tanto externo a las teorías en liza, para conceptuar con precisión los casos de inconmensurabilidad.

Como ha explicado Falguera (1999, 2012), el estructuralismo cuenta con las herramientas conceptuales necesarias para "localizar" la inconmensurabilidad y con ello también determinar la base común de dos teorías inconmensurables. Ello se debe a que reúne dos características o principios teóricos centrales: un holismo local, por el que el significado de (sólo) algunos términos de las teorías científicas están determinados por sus relaciones con otros términos de la misma, y una concepción relativizada a cada teoría de la distinción entre nociones teóricas y no-teóricas, de acuerdo con la cual la base no-teórica (no-holista) de una teoría consta de nociones disponibles o dadas con anterioridad (lógica) a la teoría en cuestión, i.e., nociones teóricas de otra(s) teoría(s) subyacente(s). Ambos aspectos son complementarios.

\footnotetext{
${ }^{3}$ Para simplificar, representaré por medio de 'T tanto los "elementos teóricos” como las "redes teóricas", que la convención estructuralista designa, respectivamente, como 'T y ' $N$ '. Cuando la diferencia resulte relevante, lo indicaré expresamente.

${ }^{4}$ Ver Kuhn $(1976,1983,1991)$. Es probable que este cambio de perspectiva obedeciera a la recepción por parte de Kuhn de los planteamientos de Sneed a través de Stegmüller, como prueba su escrito de 1976, significativamente titulado "Theory-Change as Structure-Change: Comments on the Sneed Formalism", donde Kuhn expresamente interpreta la inconmensurabilidad como un cambio de "núcleo estructural".

${ }^{5}$ Ver Mcdonough (2003). En el mismo Kuhn (1982, p. 69) encontramos formulaciones en esta línea: "lenguajes diferentes imponen al mundo estructuras diferentes".
} 
Por lo que se refiere al primer principio, el estructuralismo ha desarrollado una concepción holista del significado de los términos teóricos de las teorías, según la cual dicho significado se hace depender de las relaciones sistemáticas de tales términos con otros términos de la teoría considerada. La determinación del significado de los términos teóricos de una teoría presupone la validez de ésta y, en particular, la verdad de sus leyes fundamentales. No existe entonces modo alguno de precisar dicho significado al margen de la totalidad teórica en la que el término en cuestión se inserte. Un cambio en las leyes de la teoría comporta generalmente una variación de significado de sus términos teóricos, que arrojarán en consecuencia diferentes referencias. Semejante holismo es local en dos respectos: restringe los términos cuyo significado se determina de manera holista (sólo los términos teóricos) y también, las totalidades que están involucradas en dicha determinación (a saber, sólo las teorías o redes teóricas singulares). De este modo, el estructuralismo se previene contra los fenómenos de variación radical -y, por ende, incontrolable- de significado que aquejan al clásico holismo global (por ejemplo, el de Quine), basado en el análisis de la traducibilidad de los lenguajes -y al que remite en ocasiones Kuhn cuando formula la cuestión de la inconmensurabilidad en términos de traducibilidad interlingüística-. La inconmensurabilidad resultante de esta restricción sobre el holismo es también local, y afecta sólo a aquellas partes de la teoría que funcionan de manera holista, a saber, los conceptos teóricos de la teoría en cuestión.

Para "localizar" el holismo, y por tanto la inconmensurabilidad, el estructuralismo necesita un criterio que discierna en el seno de cada teoría los términos teóricos de los términos no-teóricos. Y aquí interviene el segundo principio antes mencionado. En cada teoría hay un número de términos que se sustraen al holismo que pende sobre los términos que en esa teoría son teóricos. El significado de los términos no-teóricos de una teoría $T$ (términos T-no-teóricos) está determinado desde fuera de $T$. Ello no implica que se trate de términos absolutamente no teóricos: pueden ser teóricos en otras teorías diferentes de $T$, de forma que su significado esté determinado por otras totalidades teóricas diferentes de $T$.

De lo anterior se sigue que si la inconmensurabilidad se da entre, digamos, dos teorías $T$ y $T^{*}$, los términos T-no-teóricos y $T^{*}$-no-teóricos podrían en principio estar excluidos de dicha inconmensurabilidad. Si tal es, en efecto, el caso, entonces habrá un vocabulario aceptable para las dos teorías con el que identificar y describir, al menos aproximadamente, aquello de lo que pretenden ocuparse ambas, sus aplicaciones compartidas. Es decir, podremos encontrar alguna función que correlacione (al menos algunos elementos de) los 'modelos parciales' de $T, M_{p p}$, con (al menos algunos elementos de) los modelos parciales de $T^{*}, M_{p p}{ }^{*}$, de forma tal que también sea posible conectar las aplicaciones propuestas por ambas, i.e., $I$ y $I^{*}$. Sin embargo, aparte de que quizá una situación semejante no refleje un caso de genuina inconmensurabilidad inter-teórica, es ciertamente posible que también los correspondientes vocabularios no-teóricos de las teorías en liza resulten mutuamente inconmensurables. Entonces ni siquiera seríamos capaces de identificar, en términos neutrales, clases de situaciones (i.e., modelos parciales) que ambas teorías pudieran considerar de su competencia. ${ }^{7}$

Sin embargo, todavía podríamos tratar de establecer alguna base empírica común a la que remitir ambas teorías. Veíamos que el significado de los términos T-no-teóricos está determinado por otras teorías diferentes de $T$, en las que tales términos son teóricos. Estas relaciones de determinación pueden representarse por medio de vínculos inter-teóricos, de acuerdo con el aparato de análisis del estructuralismo. En particular, el estructuralismo define una clase de vínculos llamados "determinantes" o "interpretativos" que desempeñan dicho cometido. También podemos hablar de la relación de "teorización”. Cuando una teoría $T_{i}$ tiene, además de algún término $T_{i}$-teórico, algún

\footnotetext{
${ }^{6}$ Lo notable es que los términos T-no-teóricos no se sustraen totalmente al holismo (en tanto que pueden ser teóricos en alguna otra teoría distinta de $T$ ), pero sí al que importa para establecer la inconmensurabilidad de $T$ (con respecto a otra teoría), es decir, el que afecta a los términos $T$ teóricos.

7 Para mayor precisión, debería distinguir entre la "base de datos" de una teoría $T$, que estaría conceptuada a base de los términos $T$-no-teóricos, y el más genérico nivel de los "fenómenos" acerca de los cuales pretende hablar la teoría, cuya descripción o identificación general no presupone aparato conceptual propio de la teoría. Más adelante, cuando distinga entre 'vocabulario característico' y 'vocabulario no-característico' de una teoría, retomaré esta cuestión.
} 
término $T_{i}$-no-teórico cuyo significado está determinado por otra teoría $T_{j}$-para la que dicho término es $T_{j}$-teórico-, se dice que $T_{i}$ es una teorización de $T_{j} \mathrm{o}$, alternativamente, que $T_{j}$ es una teoría subyacente a $T_{i}$. Entre $T_{i}$ y $T_{j}$ existe entonces un vínculo determinante (o interpretativo). Nótese que una teoría $T$ puede ser teorización de varias; o, lo que es lo mismo, tener varias teorías subyacentes, para diferentes términos T-no-teóricos.

Así pues, la situación que sugerí en el párrafo anterior, según la cual la inconmensurabilidad entre dos teorías se extendía a (algunos de) sus respectivos términos no-teóricos, puede explicarse ahora en términos de una inconmensurabilidad local entre algunas de las correspondientes teorías subyacentes. Esto es, si $t$ y $t^{\prime}$ son dos términos $T_{1}$-no-teórico y $T_{1}$ '-no-teórico, respectivamente, y son inconmensurables entre sí, ello obedecerá a una inconmensurabilidad entre las teorías $T_{0}$ y $T_{0}{ }^{\prime}$ subyacentes, donde $t$ y $t^{\prime}$ serán, por este orden, $T_{0}$-teórico y $T_{0}$ 'teórico. Este procedimiento de rastreo retrospectivo puede continuar en este nuevo nivel. Podríamos tratar de determinar si en efecto existen términos $T_{0}$-no-teóricos, por un lado, y términos $T_{0}$-no-teóricos, por el otro, que no sean inconmensurables y entre los que podamos, por lo tanto, establecer alguna conexión ontológica (u ontosemántica) que nos permita estipular algún dominio empírico común para $T_{0}$ y $T_{0}{ }^{\prime}$ y -a través de ella- para nuestro par original, $T_{1}$ y $T_{1}$ '.

Desde luego, cabe la posibilidad de que tampoco en este nivel encontremos la ansiada base común, y que tengamos que remontarnos a ulteriores teorías subyacentes cada vez más básicas. En términos absolutos, nada nos garantiza que acabemos llegando a algún nivel donde la inconmensurabilidad desaparezca, es decir, desde donde podamos ofrecer alguna descripción neutral de aquello de lo que tratan en común nuestras teorías originales. Pero hasta donde yo sé, ningún autor defiende que un resultado semejante resultara plausible, a la luz de la afirmación inicial de que las teorías en cuestión eran inconmensurables de un modo no trivial. Si intuitivamente consideramos que ambas teorías rivalizan a la hora de explicar un mismo espectro de acontecimientos, no parece verosímil que cuando nos pongamos a analizarlas carezcamos por completo de recursos conceptuales para identificar de manera neutra aquello de lo que supuestamente se ocupan. Basta con retroceder lo bastante en la cadena de teorías subyacentes.

Este procedimiento puede suscitar la intuición de que conforme nos remontemos en tal sentido, nos iremos encontrando con teorías cada vez menos "abstractas", menos alejadas de la experiencia, con cuyos términos podremos identificar las partes de la realidad acerca de las cuales pretenden decir algo las teorías que fueron declaradas inconmensurables. Es interesante constatar que ninguna idea semejante se sigue del criterio estructuralista de teoricidad, ni de las nociones de 'teorización' y 'subyacencia'. Una vez substituida la dicotomía absoluta teórico/observacional por la distinción, relativizada a cada teoría $T$, entre $T$-teórico y $T$-no-teórico, debe abandonarse la idea de que las teorías (y por lo tanto los conceptos) subyacentes están más cercanos a la experiencia, en ningún sentido epistémica o semánticamente relevante. Sólo manteniendo el prurito positivista o empirista de un lenguaje observacional neutro puede ello sostenerse. Si algo desmiente la metateoría estructural es la clásica concepción de la ciencia como una progresiva abstracción a partir de los datos puros y toscos de los sentidos (incluido el "sentido común") hacia el esclarecimiento de lo que verdaderamente hay por encima de las apariencias. Me parece inadecuado utilizar el criterio estructuralista de teoricidad para rehabilitar nada semejante a lo anterior. Con ello no pretendo afirmar que lo que se ha venido catalogando como ontosemántica de las teorías científicas se acoja a esta imagen más bien caricaturesca. Pero me gustaría discutir algunos aspectos del programa ontosemántico que a mi juicio explotan una falta de claridad con respecto a tales cuestiones.

\section{Una genealogía de los conceptos científicos}

Convendría que por un momento nos preguntáramos hacia dónde podría llevarnos una indagación semejante de sucesivas teorías subyacentes. Éste es un problema que desborda el de la 
inconmensurabilidad y concierne en general a la constitución de nuestro conocimiento científico, a su estructura. Pero también atañe a presupuestos implícitos de la empresa ontosemántica.

\subsection{Entre fundamentismo y coherentismo}

El enfoque tradicional acerca de la teoricidad, en el que todavía imperaba la dicotomía absoluta entre observacional y teórico, entendía que nuestras construcciones teóricas se alzaban sobre los datos de los sentidos, sobre la experiencia sensorial. La solvencia conceptual de nuestras teorías más abstractas, así como su posibilidad de contrastación empírica, estaba garantizada por la relación de algunos de sus términos teóricos con esa base experiencial no-teórica. Podríamos sentirnos tentados a considerar que, bajo el nuevo criterio de teoricidad estructuralista, los rasgos generales de la explicación tradicional se conservan. En la jerga del estructuralismo, ello significaría que habría una o varias teorías básicas $T^{\omega}{ }_{1}$, ..., $T_{n}^{\omega}$; los términos de tales teorías no dependería, en la determinación de su significado, de ninguna teoría anterior, pero servirían de términos $T_{i}$-no-teóricos para un conjunto de teorías $T_{i}$, a partir de las cuales las relaciones estructurales (de teorización) procederían como ya hemos explicado.

Si nos atenemos a la definición estructuralista de teoricidad, la anterior no es más que una de las situaciones posibles a las que abocaría una "genealogía" de los términos teóricos, en concreto, la posibilidad fundamentista. Podemos muy bien imaginar que la trayectoria conformada por esa sucesión de relaciones de teorización no conduce a una base última, sino que en el camino encontramos algunas circularidades. Supóngase por ejemplo una serie de teorías $T_{1}, T_{2}, \ldots, T_{n-1}, T_{n}$, en la que $T_{n}$ fuera una teorización de $T_{n-1}, \ldots, T_{2}$ una teorización de $T_{1}, y$, por último, $T_{1}$ fuera teorización de $T_{n}$. Si la estructura global de la ciencia respondiera a esta imagen, o contuviera al menos algunas cadenas de determinación como ésta, entonces el sistema de nuestro conocimiento no tendría en rigor una base empírica última, sino más bien un carácter holista, con algunos círculos de justificación. A esta posibilidad epistemológica se la suele llamar coherentista. (Una tercera alternativa, aunque lógicamente posible, debe ser descartada a tenor del hecho de que las teorías científicas son productos culturales humanos y, por lo tanto, finitas en número. Me refiero a la posibilidad de que las cadenas de determinación no poseyeran ni un fundamento último ni contuvieran bucles coherentistas, sino que prosiguieran retrocediendo ad infinito.)

Al menos desde An Architectonic for Science, los escritos en los que se aborda esta cuestión con un enfoque estructuralista tienden a inclinarse hacia la posibilidad coherentista, sobre todo porque las otras opciones parecen contravenir los dos principios estructuralistas que introducimos en la sección anterior -el holismo local y el criterio relativizado de teoricidad-y una consecuencia que parece desprenderse de éstos. Moulines (1991, p. 196) la ha formulado como la siguiente hipótesis ontosemántica bidireccional:

Por un lado: (1) para cada término cuantitativo $f$ existe una teoría científica $T$ tal que $f$ es T-teórico; y por otro lado: (2) para cada teoría científica T existe un término $f$ tal que $f$ es T-no-teórico. (Moulines 1991, p. 196)

El mismo Moulines reconoce acto seguido que esta formulación -en particular, de (1)- está restringida a términos o funciones cuantitativas, con respecto a los cuales parece ampliamente corroborada. Pero si generalizamos la hipótesis para todo tipo de términos, podemos ver claramente cómo aboca al coherentismo recién considerado.

Ahora bien, si esta hipótesis fuera correcta no sólo para los términos cuantitativos, sino también para los demás tipos de términos científicos, entonces tendríamos aquí una situación bastante peculiar: a saber, que la semántica de todo término considerado individualmente depende de la estructura conceptual de alguna teoría determinada. [...] [D] e ello se sigue que si dicha hipótesis (1) es cierta para todos los términos científicos, entonces necesariamente entramos en una especie de círculo semántico, es decir, nuestra forma relativamente moderada de holismo estaría a punto de convertirse en una forma menos moderada. (Moulines 1991, p. 197) 
Este resultado genera insatisfacción entre algunos autores, para quienes una epistemología coherentista oscurece "la conexión de las construcciones teóricas con nuestra experiencia perceptual" (Zamora Bonilla 2003, p. 48), y deja en suspenso la cuestión del contenido empírico de los conceptos científicos. Si no hay un "suelo firme" de experiencias o al menos algún punto de las redes teóricas en el que las relaciones de determinación del significado no remitan a otras teorías sino a instancias extrateóricas, entonces parece que el sistema de la ciencia (supuestamente) empírica flota en el vacío, sin verdadera fricción con la realidad. Para explicar el carácter empírico de algunas de nuestras teorías por oposición a las teorías puramente formales-, es necesario, según esta inquietud, considerar de nuevo la posibilidad de algún punto o nivel donde nuestras redes teóricas se abran a la experiencia y algunos de sus conceptos se carguen de contenido empírico. Lo cual motiva el intento de rehabilitar el fundamentismo en clave estructuralista.

Hemos visto que de acuerdo con el fundamentismo (empirista) tradicional, los conceptos que se encontraban a la base empírica de nuestras teorías habían de ser no-teóricos u observacionales de manera absoluta. ¿Qué ocurre con la versión estructuralista? ¿Cómo serían los términos de una de esas teorías básicas, $T_{i}^{\omega}$ ? Para ser fiel al espíritu empirista de la concepción tradicional, los términos descriptivos de $T^{\omega}{ }_{i}$ deberían todos ellos ser $T^{\omega}{ }_{i}$-no-teóricos, lo cual querría decir "no-teóricos en absoluto" o "puramente observacionales", puesto que por definición no hay ninguna teoría subyacente a $T^{\omega}{ }_{i}$ que pudiera suministrarle a ésta sus conceptos $T^{\omega}{ }_{i}$-no-teóricos, como sucede con el resto de teorías. Pero, dada la naturaleza del criterio de teoricidad estructuralista, la respuesta parece ser más bien la opuesta, a saber, que todos los términos descriptivos de $T^{\omega}{ }_{i}$ serían $T^{\omega}{ }_{i}$-teóricos. Todos los métodos de determinación de los términos de $T^{\omega}{ }_{i}$ presupondrían la validez de ésta, ya que, por hipótesis, no podemos apelar a ninguna otra teoría para que desempeñe esa función. $T^{\infty}{ }_{i}$ sería verdadera a priori, empíricamente irrefutable.

\subsection{Una reconstrucción inferencialista del fundamentismo. El "sentido común" como base empírica de la ciencia}

Zamora Bonilla (2003) ha defendido la existencia de esta clase de teorías básicas, cuyos términos serían todos T-teóricos. Será interesante analizar su propuesta, porque en ella se manifiestan, a mi modo de ver, ciertos equívocos bastante generalizados de la ontosemántica estructuralista.

El autor se apoya en el aparato conceptual del inferencialismo desarrollado por Brandom e inspirado en los trabajos de Sellars. De acuerdo con el inferencialismo, el significado de nuestros términos (o, alternativamente, el contenido de los conceptos que dichos términos expresan) ${ }^{8}$ está determinado por las normas que regulan su uso correcto en las prácticas lingüísticas de la comunidad. En particular, son las normas que gobiernan el uso inferencial de las expresiones en el "juego de dar y pedir razones" las que confieren a éstas su significado -lo que equivale a identificar los conceptos con roles inferenciales-. Un hablante cuenta como poseedor de un concepto cuando domina las inferencias en las que dicho concepto puede participar de acuerdo con las normas de su uso en dicho juego. Únicamente se me considerará habilitado (entitled) para usar un concepto si me comprometo (commit) con la corrección de todo ese conjunto de inferencias.

Conviene destacar que el inferencialismo invoca una noción peculiar, técnica, de 'inferencia'. Entre las inferencias con cuya corrección se compromete el usuario de un concepto dado se incluyen, de forma especialmente relevante para nuestra argumentación, aquéllas que no tienen como premisa otro enunciado, sino determinadas situaciones perceptivas que la comunidad codifica como condiciones de aplicación del concepto en cuestión y que están basadas en disposiciones fiables y ampliamente compartidas a responder a determinadas regularidades empíricas; también se incluyen, asimismo, aquellas inferencias que por conclusión no tienen un enunciado, sino un curso de acción. De donde resultan tres clases generales de movimientos inferenciales: (i) de enunciado(s) a enunciado,

\footnotetext{
${ }^{8}$ En lo que sigue, hablaré indistintamente de 'contenido de un concepto' y 'significado de un término', y me deslizaré de una expresión a otra omitiendo las diferencias entre ambas. Pero ello no comprometerá el núcleo de mi argumentación, que podría reformularse en términos que se hicieran cargo de la distinción.
} 
(ii) de situación(es) perceptiva(s) a enunciado, y (iii) de enunciado(s) a curso de acción. Así, la teoría recoge bajo la noción de 'inferencia' todos los usos posibles de un término/concepto, incluidos aquéllos usualmente catalogados como no-inferenciales, a saber, sus usos en el contexto de informes observacionales y sus usos como reglas prácticas de acción, que pueden respectivamente ser considerados como movimientos de "entrada" y "salida" de nuestro sistema conceptual.

Zamora Bonilla pretende reformular el criterio estructuralista de T-teoricidad conforme a estas nociones inferenciales. Un concepto/término $t$ será teórico con respecto a una teoría $T$ si, y sólo si, todo hablante debe comprometerse con la aplicabilidad de la teoría $T$ al hacer uso de $t .^{9}$ En términos enunciativos, ello equivale a que todo uso legítimo de $t$ conlleva el compromiso con las leyes (en un sentido amplio) de $T$; en términos modelísticos, que desde el momento en que uso $t$ para caracterizar un sistema $x$, estoy comprometido con que $x$ es un modelo real de T. Sobre la base de este criterio, Zamora Bonilla se aventura a afirmar la existencia de teorías básicas cuyos conceptos serían todos $T$ teóricos. La idea es que determinadas agrupaciones de conceptos están tan inferencialmente trabados entre sí y tan ligados a nuestra experiencia más cotidiana, que el uso de cualquiera de ellos -incluido, especialmente, su uso no-inferencial- presupone aceptar la aplicabilidad de todos los demás.

Estas "teorías" implícitas en nuestras prácticas habituales constituyen algo así como unidades mínimas de "sentido común", que condensan nuestra confianza en regularidades básicas de la naturaleza y de las que se nutren nuestros esfuerzos teóricos más sistemáticos y abstractos. A tales teorías, el uso de cualquiera de cuyos conceptos conlleva el compromiso con las inferencias codificadas por todos los demás, y ningún otro, Zamora Bonilla las llama "teorías básicas". Entre las teorías básicas, hay algunas, quizá ciertas partes de las matemáticas, que no tienen contenido empírico, pues sus conceptos no permiten movimientos inferenciales desde escenarios perceptuales. En contraste, las "teorías básicas observacionales" son teorías básicas cuyas aplicaciones pretendidas se completan en su totalidad mediante sus relaciones con "escenarios perceptuales". Todos los conceptos de una teoría semejante siguen siendo T-teóricos, por cuanto no puedo aplicar ninguno ellos a la descripción de un sistema sin comprometerme ipso facto con que dicho sistema es un modelo de la teoría. En palabras de Zamora Bonilla (2003, p. 60), "an observational theory is simply a basic theory whose intended applications are given through some perceptual scenarios; those applications are just 'data models', but formed by data of the most primitive kind" (la cursiva me pertenece). A continuación, califica como "término observacional" a todo aquél que pertenece a una teoría observacional básica o es introducido mediante una definición explícita a partir de términos observacionales.

Las teorías observacionales básicas, que proporcionan conceptos observacionales tout court, constituyen, según Zamora Bonilla, el ansiado punto de conexión entre el edificio de la ciencia y la experiencia. Las teorías científicas son propiamente empíricas porque las cadenas de determinación del significado de sus términos desembocan en conceptos observacionales, pertenecientes a "teorías" de "sentido común" y de nuestro lenguaje ordinario. Éstas son los únicos puntos por las que la constricción de la experiencia interviene en nuestro sistema conceptual.

[M]y notion of 'observational basic theories' attempts to capture the unavoidable connection between scientific concepts (those which are theoretical with respect to some 'scientific' theory) and ordinary linguistic practices. If this notion is right, scientific knowledge is built on common sense, although the former can serve to correct the latter when it proves that some common sense assumptions may lead to contradictions (Zamora Bonilla 2003, p. 63; cursivas en el original). ${ }^{10}$

\footnotetext{
${ }^{9}$ En rigor, el criterio propuesto por Zamora Bonilla (2003, p. 57) afirma que un término $t$ es teórico con respecto a $T$ syss: (a) si al usar $t$ en la descripción de un sistema $x$ no se asume que $x$ es un modelo (real) de $T$, entonces no se estará habilitado para usar $t$ (no se habrá entendido su significado); $y$ (b) " $T$ is the stronger theory for which (a) is true". La condición (b) se introduce porque, según Zamora Bonilla (a), es verdadera para cualquier tautología o para cualquier consecuencia lógica de $T$.

${ }^{10}$ La última cláusula se dirige contra la infalibilidad tradicionalmente atribuida a los conceptos observacionales. Las teorias observacionales que Zamora Bonilla caracteriza son falibles; es más, a menudo han sido falsadas, lo cual, según él, no debería sorprendernos si consideramos que su cometido consiste en hacer frente a las regularidades empíricas del medio local, y pueden revelarse erróneas con tal de que se extienda el alcance de su aplicación. No discutiré este punto; únicamente sugeriré que, más que falsables, las teorías básicas que presenta Zamora Bonilla serían substituibles. Pues una de las características de tales teorías parece ser que ninguna afirmación que explicitara el contenido de alguno de sus
} 
En esta concepción participan dos puntos de vista complementarios que, en mi opinión, ponen de manifiesto una forma desorientadora de entender, por un lado, el papel del "sentido común" o el "lenguaje ordinario" en la constitución de las teorías científicas y, por el otro, el contenido empírico de nuestros conceptos y sus relaciones con la experiencia. Estos malentendidos, especialmente el segundo de ellos, recorren la discusión tradicional acerca de la dicotomía entre fundamentismo y coherentismo en el marco del estructuralismo, y obedecen, de nuevo, a una inadecuada atención al carácter pragmático de nuestra actividad conceptual, de la que se desprende una errónea ontosemántica de las teorías científicas.

El primer malentendido se refleja en la imagen según la cual la ciencia descansa o se alza sobre la base semántica que le ofrecen nuestros conceptos de "sentido común", como si las teorías de "sentido común" tuvieran una estructura análoga a las teorías científicas de modo tal que pudieran subyacer a ellas (o éstas pudieran ser teorizaciones de aquéllas). ${ }^{11}$ No me parece adecuado concebir la relación entre los "conceptos observacionales", tal y como los describe Zamora Bonilla, y los conceptos científicos del mismo modo en que el estructuralismo caracteriza la relación de determinación de significado de un término $T$-no-teórico por una teoría $T^{\prime}$ donde dicho término es $T^{\prime}$-teórico -es decir, recurriendo a la noción de vínculo inter-teórico-. Nuestros conceptos de "sentido común" o de "lenguaje ordinario" desempeñan una función pragmáticamente esencial en el aprendizaje, el uso y la aplicación de las teorías científicas -y por lo tanto en la determinación semántica de las mismas-, pero ese papel no puede reconstruirse mediante las nociones modelo-teóricas que el estructuralismo emplea en el ámbito de teorías científicas reales, las cuales ofrecen una rigidez conceptual apta para ese tipo de análisis. Los conceptos ordinarios o de "sentido común" desempeñan el papel generalmente atribuido por el estructuralismo al vocabulario no-característico de las teorías. En cambio, el trato que Zamora Bonilla dispensa a ese supuesto repertorio de teorías básicas (observacionales o no) constituidas por el "sentido común” sugiere que éstas se identifican sin más con esa clase última $T^{\omega}{ }_{1}, \ldots, T^{\omega}{ }_{n}$ que conjeturábamos al presentar la posición fundamentista. El resultado es que toda la teorización operada por la ciencia tiene como última base (empírica) conceptos (T-teóricos) observacionales.

El segundo malentendido, que se alinea con el anterior, concierne al modo en que se insiste en confinar el ingrediente observacional -como fuente del contenido empírico- a un sector determinado de nuestro sistema conceptual -el constituido por esas teorías básicas-, y sólo a éste. Con ello se restaura la partición positivista del conjunto de nuestros conceptos: por un lado, estaría un reducto de conceptos observacionales a través de los cuales la experiencia y la constricción empírica ingresa en nuestro sistema conceptual; por otro lado, se encontraría el resto de conceptos, y en particular los de las teorías científicas, dotados de contenido empírico únicamente en tanto que mantienen relaciones semánticas con los conceptos del primer grupo. Asimismo, los vínculos inter-teóricos que unieran los conceptos de las 'teorías observacionales básicas' con los conceptos de las teorías científicas desempeñarían el papel de las clásicas 'reglas de correspondencia', que en la concepción heredada servían para anclar el vocabulario teórico en el observacional.

Frente a esta concepción debe señalarse que, por una parte, el empleo de la noción de 'vínculo inter-teórico' y de la relación de 'teorización' (o 'subyacencia') responde a cuestiones concernientes a la constitución estructural -semántica, si se quiere- de nuestras teorías científicas y a las relaciones metodológicas entre ellas existentes, pero no atañe la búsqueda de bases empíricas u observacionales absolutas que pudieran servir de soporte evidencial a todo nuestro sistema científico. El criterio estructuralista de teoricidad da mejor cuenta que el de la tradición heredada de ciertos aspectos de las

conceptos podría negarse conservando la identidad del concepto en cuestión. Brandom (2000a, cap. 1, sec. XI) argumenta en este sentido con relación a algunos conceptos despectivos, como 'boche', utilizado para referirse de manera peyorativa a los alemanes: no podemos seguir usándolos rehusando a la vez comprometernos con las inferencias que son constitutivas de su significado; si discrepamos de ellas, nuestra única opción es negarnos a usar el concepto.

${ }^{11}$ Lo más concreto que Zamora Bonilla (2003, p. 62) dice en relación con este punto es lo siguiente: "Nonetheless, observational basic theories cannot be 'scientific' in the sense in which classical mechanics or plate tectonics are; instead, they are usually networks of assumptions belonging to our use of ordinary language, fragments of 'common sense', and so they are 'pre-scientific". 
prácticas científicas, en particular, de los procedimientos de determinación y contrastación. Pero, por otra parte, ni siquiera si se defiende que la relación entre los conceptos de "sentido común" y los de las teorías científicas es relevante para la comprensión de éstas, resulta adecuada su subsunción bajo las nociones de 'teorización' y 'vínculo inter-teórico', en la que incurre el primer malentendido que acabo de señalar. Comenzaré defendiendo este punto.

\section{Una ciencia sin "base"}

Suele aceptarse que, en el aprendizaje, la aplicación y el desarrollo de las teorías científicas interviene un conjunto de habilidades de trasfondo que tienen que ver con los recursos conceptuales suministrados por lo que se viene llamando "lenguaje ordinario" o "sentido común". La cuestión es: ¿cuál es el papel de tales conceptos? La primera opción ya ha sido considerada al tratar la propuesta de Zamora Bonilla. Una variante de ésta, que encontramos en Díez (2002), consiste en decir que ellos son los "ancestros populares" de algunos conceptos característicos de teorías propiamente científicas. La supuesta continuidad entre el conocimiento ordinario y el que suministran las teorías científicas, además de ejemplos como el de masa, cuya versión "popular" juega un papel análogo en las explicaciones cotidianas al que su pariente más técnico desempeña en las aplicaciones de la mecánica clásica, han sido aducidos a favor de esta interpretación. Algunos conceptos científicos comportarían un refinamiento de ancestros precientíficos; éstos resultarían esenciales a la hora de especificar la identidad de aquéllos, mediante, por cierto, vínculos inter-teóricos. ${ }^{12}$

Defenderé otra opción, que conserva la mencionada idea de continuidad y permite entender casos como el de masa, y que consiste en asumir que los conceptos precientíficos, de "sentido común", constituyen una vía práctica de acceso al uso de los conceptos característicos de las teorías científicas. El acervo conceptual del lenguaje cotidiano suministra el llamado 'vocabulario no-característico', que permite al lego introducirse en una teoría científica y adquirir la capacidad de usar sus conceptos característicos. Ciertamente dicho vocabulario ofrece una primera y aproximada descripción de los aspectos del mundo que la teoría pretende explicar y permite, por lo tanto, señalar de manera tentativa y, digamos, propedéutica sus ámbitos paradigmáticos de aplicación. Pero de aquí no se sigue que la relación entre el vocabulario $T$-no-característico y el $T$-característico respecto de una teoría $T$ se asimile a la relación constitutiva que existe entre éste y el vocabulario T-no-teórico, presuntamente $T^{\prime}$-teórico de alguna teoría $T^{\prime}$. Una razón importante para no suscribir dicha asimilación es que el vocabulario T-nocaracterístico, a diferencia del T-no-teórico, no forma parte de la formulación canónica de la teoría y por ende de su identidad modelo-teórica; y en la medida en que el contenido del vocabulario T-noteórico viene determinado por algunos vínculos de $T$ con otra(s) teoría(s), tales vínculos también figurarán en la representación modelo-teórica completa de $T$, contribuyendo a fijar su identidad.

\subsection{Dependencia pragmática global}

A la luz de la función que desempeña el vocabulario no-característico en el acceso práctico al vocabulario característico de las teorías, propongo recoger las relaciones existentes bajo la noción de dependencia pragmática. ${ }^{13}$ La relación que los conceptos característicos de una teoría mantienen con conceptos del lenguaje corriente o del "sentido común" reside en que éstos ofrecen las condiciones de adquisición y acceso al contenido específico de aquéllos. Dominar prácticamente un vocabulario (el característico de la teoría) presupone dominar el otro (el vocabulario de "sentido común"). ${ }^{14}$ Ello no

\footnotetext{
${ }^{12}$ A esta interpretación se inclina Díez (2002, p. 19s.), cuando discute el "folk-ancestry component" de la identidad de los conceptos científicos.

${ }^{13}$ En sus inéditas John Locke Lectures, Robert Brandom plantea en términos parecidos esta clase de relaciones de dependencia entre distintos vocabularios y entre éstos y las prácticas correspondientes. Como señalo en la bibliografía, puede encontrarse una versión digital de estas conferencias en Internet. Algunos anticipos de esta elaboración se encuentran en Brandom (2000b). En lo que sigue, me aparto en aspectos centrales de su explicación, que no considero aquí oportunos.

${ }^{14}$ Esta apelación a 'vocabularios' no implica una concepción enunciativa de las teorías científicas, según la cual éstas consisten en cálculos lógico-sintácticos (generados por un "vocabulario") junto a una interpretación establecida mediante reglas de correspondencia con base en otro "vocabulario": el "observacional”. Por 'vocabulario' no entiendo aquí cualquier conjunto de símbolos primitivos que puedan
} 
quiere decir que el contenido de un vocabulario o sistema de conceptos sea semánticamente reducible o traducible en términos del otro. Podemos en efecto suponer que el vocabulario pragmáticodependiente incorpora nuevos recursos expresivos que le dotan de un potencial semántico del que carece el otro.

Propongo precisar esta relación del modo siguiente. Un vocabulario $V^{\prime}$ depende pragmáticamente de un vocabulario $V$ syss hay un conjunto de prácticas $P$ tal que la capacidad de participar o intervenir en $P$ es suficiente para ser considerado usuario de $V$ y necesaria para ser considerado usuario de $V$ '. En tal caso, también diremos que $V$ es pragmáticamente autónomo respecto de $V$ '. Uno tiene que saber "jugar" a $V$ para poder "jugar" a $V$ '. Para que se me pueda considerar poseedor de los conceptos propios del vocabulario $V^{\prime}$, he de acreditar mi destreza en el uso de los conceptos del vocabulario $V$. Nótese por otra parte que, de acuerdo con esta definición, el uso de $V^{\prime}$ puede requerir la movilización de capacidades prácticas adicionales, distintas de las que se condensan en $P$.

En el caso que nos ocupa, mi tesis es que el vocabulario de las teorías científicas es pragmáticamente dependiente del vocabulario del lenguaje ordinario. Esta tesis se inscribe en un enfoque pragmatista según el cual los elementos de un vocabulario tienen el significado que tienen en virtud del modo en que se usan. Para completar tal planteamiento, podríamos extender nuestro análisis sosteniendo que el vocabulario de la semántica (incluida la teoría de modelos) es pragmáticamente dependiente del vocabulario de la pragmática -tal y como ésta se especifica en la corriente inferencialista, es decir, en términos de compromisos y habilitaciones que modifican el estatus normativo en el marco de prácticas o juegos de lenguaje-. Una consecuencia de esta tesis es que mediante los recursos del vocabulario de la pragmática puede accederse al vocabulario de la semántica, mientras que la inversa no es posible. El vocabulario (normativo) de los usos y las prácticas es pragmáticamente autónomo con respecto al vocabulario del significado y la referencia.

Ello explicaría que las relaciones de determinación de contenido acabaran eventualmente sustrayéndose al análisis modelo-teórico en ciertos extremos en los que se diluye el tipo de rigidez en las construcciones teóricas que el estructuralismo contempla. Podría ser difícil encontrarle sentido a la aplicación de tales recursos para ilustrar las relaciones de dependencia pragmática entre vocabularios, especialmente cuando (al menos) uno de ellos no contiene elementos con el grado de teoría. Cabe la posibilidad de que la representación modelo-teórica no pueda extenderse hasta ese punto, pero ello no tendría por qué comprometer la aptitud de los métodos estructuralistas de representación para elucidar la estructura conceptual de las teorías científicas realmente existentes. Tampoco tendría por qué poner en un brete el contenido empírico de las teorías científicas, ni dejar en suspenso la determinación del contenido de sus conceptos, generando las perplejidades asociadas al dilema epistemológico a la que parecía abocarnos la reconstrucción genealógica de las teorías. Pues el análisis en términos de dependencia pragmática puede aplicarse de manera local, para ilustrar aquellos casos en los que la reconstrucción estructuralista parece tocar fondo y nos sentimos impelidos a postular una base última que sirva de lecho empírico a nuestras teorías científicas.

\subsection{Transiciones locales}

Supóngase, en efecto, que encontramos una teoría científica $T_{x}$ dotada en principio de todas las características que el estructuralismo discierne, pero que posee (al menos) algún término $T_{x}$-no-teórico $t$ que no puede ser puesto en relación con ninguna otra teoría $T^{\prime}$. Ello implicaría que contamos con

combinarse conforme a ciertas reglas para formar oraciones, sino más bien cualquier medio semánticamente independiente de expresión. Normalmente un vocabulario estará basado en el uso articulado de símbolos conforme a ciertas reglas; la apelación expresa a los usos de los símbolos pretende subrayar su importancia esencial en la especificación de un vocabulario. Dos vocabularios diferentes pueden contener la misma lista de símbolos siempre que difieran en el uso que cada uno les depara. No es el conjunto de sus símbolos lo que determina el poder expresivo de un vocabulario (qué es lo que puede expresar), sino el modo en que se usan (i.e., los símbolos junto a su uso). Esto es consecuencia de la tesis que Brandom (p.e., 2008, p. 9) ha llamado "pragmatismo semántico": lo que un vocabulario es capaz de expresar (significado) está determinado únicamente por el modo en que se usa. Así, el vocabulario de las teorías científicas puede concebirse como un conjunto expresivamente independiente de recursos de tipificación, caracterización y otros procedimientos de constricción que permiten expresar estructuras complejas. 
métodos de determinación del valor de $t$ que, si bien no presuponen la aplicabilidad de $T_{x}$, tampoco se identifican con modelos de ninguna otra teoría existente, sino con habilidades prácticas ordinarias (cuya aplicabilidad no tiene, me parece, sentido cuestionar en los mismos términos). La capacidad de llevar a cabo tales prácticas es condición para manejar el término t, pero no podemos de momento reconstruir esa relación mediante la noción de 'vínculo', ya que la semántica del vocabulario asociado a esas capacidades prácticas no arroja la clase de modelos que el aparato estructuralista requiere. En tal caso, $t$ poseería una naturaleza híbrida, a medio camino entre el vocabulario $T_{x}$-característico y el $T$-no característico: por un lado, $t$ forma parte de las estructuras de caracterización de los modelos potenciales de $T_{x}$; por el otro, no podría satisfacerse el requisito de correlacionar dichos modelos potenciales con los de otra teoría por lo que a $t$ se refiere. ${ }^{15}$ Las condiciones de uso de $t$ vienen determinadas por el vocabulario corriente, pero son "exportadas" al vocabulario característico de $T_{x}$. Puesto que convenimos en que el vocabulario de "sentido común" del que depende pragmáticamente el uso de $t$ no forma parte de identidad modelo-teórica de $T_{x}$, ésta quedaría hasta cierto punto abierta.

No es sin embargo forzoso que esta situación sea permanente. Podrían desarrollarse esfuerzos teóricos encaminados al esclarecimiento de algunos ámbitos para los que hasta entonces sólo contábamos con nuestras aptitudes de "sentido común", de manera que $t$ terminara por formar parte como término teórico de alguna teoría científica. Según esto, la empresa teórica de la ciencia no procedería sólo "hacia arriba", hacia mayores cotas de "abstracción", sino también "hacia abajo", hacia la operacionalización y teorización de recursos conceptuales precientíficos, con el objeto de establecer de manera más precisa la identidad de teorías como la que hemos asumido en la suposición del párrafo anterior. La actividad científica ganaría para su causa, por decirlo así, territorios cada vez más amplios de "sentido común", modificando el escenario conceptual global. Es éste, por cierto, uno de los modos en los que la actividad científica podría corregir nuestros conceptos ordinarios.

Alternativamente, también podría suceder que en el decurso de la actividad científica se hallaran modos de determinar el valor de $t$ mediante modelos de teorías ya existentes en disciplinas alejadas de la que hospeda a t, lo cual podría suscitar la impresión de que se producen "bucles" viciosos de determinación. Pero esta impresión, por lo que concierne al carácter pernicioso de dichos "bucles", parece deudora de una doble exigencia: por una parte, (a) el "edificio" global de la ciencia debe alzarse, lineal y jerárquicamente, sobre un único elemento básico, por lo que el recurso a modelos de teorías jerárquicamente superiores a fin de determinar la identidad de teorías de nivel inferior conllevaría una circularidad (epistemo)lógicamente nociva, además de que no se vislumbraría posibilidad alguna de desarrollar teorías "por debajo" de ese supuesto elemento básico -como sugerí en el párrafo anterior-. Por otra parte, (b) la cercanía de esta base a la experiencia garantizaría la solvencia empírica del resto del edificio. La primera parte de esta exigencia es un desarrollo del primer malentendido al que me referí al final de la sección 3.2. La segunda parte se corresponde con el segundo malentendido, del que me ocuparé más adelante; ahora me gustaría concentrarme en (a).

La figura 1 ilustra la situación a la que (a) apunta, como caso extremo e idealizado. ${ }^{16}$ La flecha discontinua indica el vínculo supuestamente retrógrado. Tres rasgos minan de forma independiente la concepción esquematizada en dicha figura. Primero, el carácter lineal de la red de teorías, para las que sólo hay una base, que, en segundo lugar, mantiene con las teorías de nivel superior una relación de

\footnotetext{
${ }^{15}$ Coincido con Zamora Bonilla (2003) en que algunos grupos de conceptos empleados en el ejercicio de prácticas ordinarias pueden encontrarse tan inferencialmente trabados que la aplicación de uno de ellos implique el compromiso con las inferencias codificadas por (es decir, con la aplicabilidad de) los demás; discrepo de él en que -por esta circunstancia entre otras- no adjudico a tales complejos conceptuales el rango de "teorías", en el sentido estructuralista. Nuestra $t$ no se corresponde con ninguno de esos conceptos ordinarios en particular, por más que la capacidad de usar algunos de éstos sea condición necesaria para la aplicación de t; tampoco puede precisarse el significado de $t$ a base de vínculos inter-teóricos entre complejos conceptuales de "sentido común" y la teoría $T_{x}$. Con relación a estos complejos conceptuales de "sentido común”, de acuerdo incluso con la presentación de Zamora Bonilla (2003), no procede la distinción entre modelos potenciales $\left(M_{p}\right)$ y modelos reales $(M)$, que es esencial a la caracterización estructural de las teorías científicas -y también, por cierto, a la definición de los vínculos inter-teóricos, que han de estar constituidos por (al menos) pares ordenados de modelos potenciales-.

${ }^{16}$ En ningún caso pretendo asimilar esta concepción extrema al estructuralismo ni adscribírsela a ningún autor de esta corriente. Se trata de una posición depurada que traigo a colación en aras de la argumentación y con propósitos de contraste.
} 
determinación semántica apresable mediante vínculos inter-teóricos. En tercer lugar, la línea horizontal continua debajo de $T_{0}$ representa que ésta es una base última, "por debajo" de la cual no pueden surgir nuevas teorías.

La figura 2 esquematiza la situación que prefiero contemplar. No encontramos en ella ningún elemento único a la base de todas las familias de teorías. Las teorías sub-1 se encuentran en una posición análoga a nuestra $T_{x}$. $T^{B}{ }_{1}$, en particular, presenta una relación de teorización procedente de una teoría de un ramal independiente, $T_{3}{ }_{3}$. Los puntos suspensivos al pie de cada una de las teorías sub-1 indican que pueden elaborarse teorías sub-0 en las que nociones $T_{1}$-no-teóricas sean $T_{0}$-teóricas (sin que el ' 0 ' quiera indicar que se trate de teorías "últimas" o "básicas"). Pongo entre paréntesis los puntos bajo $T^{B}$ para sugerir que en este caso puede haber quedado "cerrada" por el vínculo desde $T^{C}{ }_{3}$,

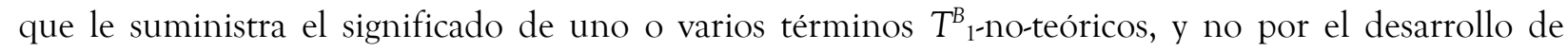
alguna teoría $T^{B}$. En realidad, las teorías sub-1 no son "bases" en un sentido semántica o epistemológicamente fuerte, sino más bien de manera contingente y provisional. Por otro lado, el modo en el que el "sentido común" está a la base de las teorías científicas no puede, según he defendido, asimilarse al que presenta la figura 1. Para empezar, no podrían especificarse vínculos interteóricos entre el "sentido común" y las teorías científicas. ${ }^{17}$

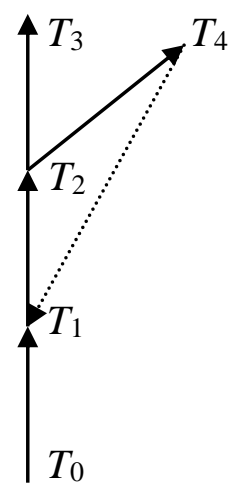

Figura 1.

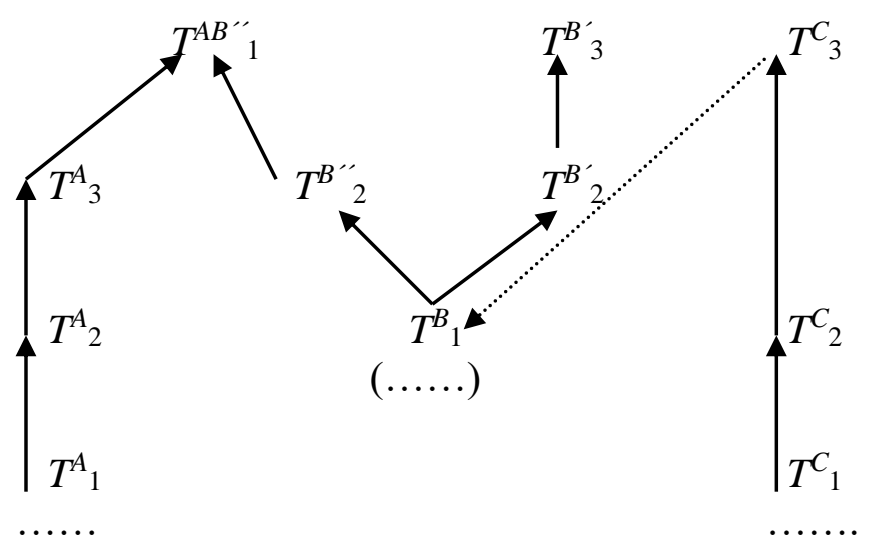

Figura 2.

Vemos que el modo de concretar, en términos de dependencia pragmática, la metáfora de que los esfuerzos teóricos de la ciencia tienen por "base" conceptos de uso ordinario no implica asumir que haya uno o varios elementos puntuales sobre el que semánticamente se construya todo el sistema de la ciencia mediante teorización. En el caso que venimos discutiendo, la teoría $T_{x}$ importa las condiciones de uso de $t$ desde el acervo conceptual ordinario, y lo hace de manera local. Pero ello se produce en un momento de transición pragmática entre el vocabulario de "sentido común" y el vocabulario de las teorías científicas. Si algo mereciera el nombre de "base" con relación a las teorías sub-1 de la figura 2, serían las teorías que surgieran bajo ellas en el nivel sub-0 u otras teorías ya existentes que las engarzaran mediante vínculos inter-teóricos. El recurso puntual o local de algunas teorías científicas a recursos prácticos de "sentido común" no indica que ésta sea la base última; indica más bien un punto de transición entre vocabularios, provisional y sometida a revisión semántica dentro del propio vocabulario de destino. Ningún concepto específico de nuestro vocabulario de "sentido común" se corresponda con $t$, aunque los recursos conceptuales para la aplicación de $t$ en $T$ arraiguen en las prácticas cotidianas de uso del lenguaje corriente. Incluso si algún elemento del vocabulario ordinario, digamos $t^{\prime}$, tiene el mismo nombre que $t$, y reconocemos alguna reminiscencia de significado, dicho significado no ha de ser el mismo, pues las coordenadas estructurales -el "espacio lógico", por decirlo

\footnotetext{
${ }^{17} \mathrm{Al}$ igual que las teorías del nivel sub-1 de la figura 2, $T_{x}$ se diferencia de las teorías básicas de Zamora Bonilla (2003) en que, si bien no existe ninguna teoría $T^{\prime}$ que determine el significado de algunos de sus términos -y por lo tanto quizá nos sintamos reticentes a considerarlos del todo $T_{x}$-no-teóricos-, no por eso han de ser éstos clasificados como $T_{x}$-teóricos.
} 
así- del vocabulario de $t$ difieren de las de $t^{\prime}$. Diríamos más bien, a lo sumo, que $t$ se relaciona pragmáticamente con $t^{\prime}$, pero no que tienen el mismo contenido semántico o la misma facultad expresiva: pertenecen a vocabularios diferentes. La noción la dependencia pragmática entre vocabularios permite que, cualquiera que sea la relación de dependencia pragmática que impere entre dos vocabularios, cada uno conserve su independencia (onto)semántica.

De acuerdo con esto, la hipótesis ontosemántica bidireccional enunciada por Moulines (1991, p. 196) que recogí en la sección 3.1 se revelaría o bien falsa, o bien trivialmente verdadera, según nos decantásemos, respectivamente, (a) por adjudicarle a $T_{x}$ el estatus de teoría científica, en cuyo caso tendríamos -contra su cláusula (1) - una tal teoría para alguno de cuyos términos $T_{x}$-no-teóricos no existiría ninguna teoría $T^{\prime}$ en la que fuera $T^{\prime}$-teórico, o (b) por negárselo, precisamente a tenor de que contiene un término con esas características.

Una manera sugerente de explorar esta alternativa consiste en distinguir entre los puntos de vistas sincrónico y diacrónico. Cuando emprendemos la reconstrucción metateórica de una teoría real $T$, es una buena hipótesis metodológica la que nos conduce a buscar teorías subyacentes para sus términos T-noteóricos, a fin de que podamos introducir en la caracterización completa de $T$ los vínculos interteóricos determinantes pertinentes, que nos permitirán contemplarla como una estructura acabada. Sin embargo, tenemos que asumir que hay estadios en la evolución de algunas teorías en los que éstas presentan características cercanas a $T_{x}$, que constituye un punto de transición entre el vocabulario de "sentido común" y el vocabulario de la ciencia. Las teorías científicas, lo mismo que los vínculos interteóricos, se crean en el tiempo; lo mismo que las teorías científicas, son construcciones históricas. Si queremos, podemos decir que, sincrónicamente, $T_{x}$ es una teoría "abierta" que, diacrónicamente, está llamado a vincularse con alguna otra teoría $T^{\prime}$ mediante un vínculo inter-teórico que la "cierre". De aquí podemos deslizarnos a decir que, contemplada sincrónicamente, aún no es una teoría acabada, aunque, considerando sus posibilidades diacrónicas de evolución, aceptemos considerarla como tal.

Cuando ascendemos a un plano especulativo general y nos planteamos qué aspecto epistemológico tendrá algo así como "la estructura global de la ciencia", se difumina la frontera entre ambos puntos de vista, introducimos subrepticiamente el diacrónico en lo que asumimos es sincrónico, incurrimos en los equívocos asociados a la figura 1 y obtenemos el tipo de calambres intelectuales que ya conocemos. La metateoría estructural no tiene la culpa de ello. Quizá el culpable sea la imagen de un momento último en el que se cerraría la evolución de la ciencia y nos encontraríamos con "el sistema acabado de la ciencia". Me temo que tal idea es infundada, y responde más al mito positivista del "estado científico final" del Espíritu que a lo que sabemos de Sus tortuosas (r)evoluciones.

\subsection{Independencia (onto)semántica}

Adonde no llega el análisis semántico en términos modelo-teóricos puede acceder el análisis pragmático, planteado en términos del conjunto de habilidades que es necesario poner en juego -el vocabulario que es necesario dominar- para alcanzar el dominio del vocabulario objeto de análisis. En este punto, el análisis conceptual se plantearía no como una reducción de un sistema referencial a otro supuestamente más "básico", sino como la remisión de la práctica de uso de un vocabulario a la práctica de uso de otro. No encontraríamos entonces una o varias teorías básicas que dieran el significado y las referencias de las teorías de nivel superior, sino vocabularios o rudimentos conceptuales desde cuyo uso podríamos acceder al uso del vocabulario más restringido. Por supuesto, ésta es una cuestión abierta a futuras investigaciones y a la consecución de reconstrucciones de redes teóricas completas -si es que ésta puede llevarse a término-.

Está por ver cómo procedería en el detalle un análisis semejante. El recurso a la teoría de conjuntos, a la teoría de modelos o a otros medios formales de representación (teoría de categorías, por ejemplo) no tiene por qué descartarse de antemano, a condición de que se interpreten como expedientes para la reconstrucción en un nuevo plano expresivo de esas relaciones pragmáticas en virtud de las cuales el pragmatismo nos anima a considerar que se constituye el significado. El inferencialismo, en particular, propone colocar en primer plano nociones inferenciales a la hora de 
elucidar la articulación de las prácticas. Ello contraviene la presuposición generalizada de que las relaciones inferenciales van precedidas en el orden de explicación por las relaciones denotativas, y que son éstas las que tratan de reflejar las técnicas modelo-teóricas. El enfoque alternativo pasa por aceptar que, si la teoría de modelos es una teoría semántica en absoluto, lo es porque define y especifica en términos precisos la relación (o noción) inferencial de 'consecuencia'. ${ }^{18}$ La noción de 'denotación' adquiere sentido cuando se emplea como elucidación de las relaciones de consecuencia. El mérito de las corrientes metateóricas semantistas consistió precisamente en emplear los recursos de la teoría de modelos para esclarecer la estructura lógica de las teorías científicas y las relaciones inferenciales existentes entre ellas, que la tradición heredada pretendía abordar de manera directa mediante su análisis en términos enunciativos. Considerar las nociones denotativas como primitivas no añade nada a lo que ya tenemos cuando las usamos para articular explícitamente relaciones inferenciales. ${ }^{19}$

Desde aquí, el panorama acerca de la ontosemántica de las teorías ya no puede dibujarse en los términos empiristas tradicionales. La autonomía pragmática de un vocabulario con respecto a otro no comporta su mayor cercanía a "la experiencia". Que el vocabulario de "sentido común" sea autónomo respecto del vocabulario de las teorías científicas quiere decir que no podemos adquirir éste sin poseer aquél; aprendemos el juego de la ciencia a partir del juego del lenguaje corriente. Ello tampoco entraña su autonomía o primacía en el plano ontosemántico de fijación de clases (más o menos últimas) de referencia. Un vocabulario $V^{\prime}$ pragmático-dependiente de otro $V$ podría estar dotado de mayor poder y fineza expresiva que éste, lo que le permitiría decir lo que $V$ no puede. En términos modelísticos, esta situación equivaldría a lo siguiente: $V^{\prime}$ incluye términos/conceptos que permiten caracterizar estructuras inaccesibles para $V$. Por tanto, (al menos) algunos de los eventuales modelos de $V^{\prime}$-los sistemas concretos que satisfagan tales estructuras- quedarán, como tales, fuera del alcance de $V$. Se objetará que la potencia semántica de $V^{\prime}$ no es mayor que la de $V$, sino diferente, de modo que también en la dirección inversa se verifica la negligencia: también los modelos de $V$ están, como tales, fuera del alcance de $V^{\prime}$. Pero, entonces, ¿por qué habríamos de preferir la semántica -y por tanto la ontología- de $V^{\prime}$ sobre la de $V$ ?

En primer lugar, debería quedar claro que las relaciones de dependencia pragmática no reproducen las clásicas 'reglas de correspondencia'. Como escribí un poco más arriba, cada vocabulario conserva su independencia (onto)semántica, su autonomía expresiva, a despecho de las relaciones de dependencia pragmática que imperen entre ellos.

En segundo lugar, el vocabulario de la ciencia comporta una evolución de nuestros recursos expresivos, un incremento de nuestras capacidades de representación, que pone en juego procedimientos de tipificación, matematización, metrización, etc. para los que el lenguaje cotidiano se muestra menos apto. Podemos comprender esta clase de progreso expresivo si comparamos la diferencia que existe entre un lenguaje sin operadores de cuantificación, predicación relacional o modalidad, por ejemplo, y otro que los incorpore. El vocabulario de la ciencia comporta un despliegue conceptual, una extensión de nuestra virtualidad expresiva mediante la incorporación de nuevos expedientes semánticos. Las razones que nos conducen a hacerles caso a las teorías científicas por encima de nuestro "sentido común" son las mismas que nos llevan a concederles un mayor crédito (onto)semántico y a adherirnos a la ontología que son capaces de expresar.

En tercer lugar, me parece que sólo si entendemos que el vocabulario de "sentido común" mantiene con la "experiencia" una relación privilegiada, podríamos concederle a éste una primacía (onto)semántica sobre el vocabulario de las teorías científicas. Desde una perspectiva pragmatista dejan de tener sentido algunos de las distinciones sobre las que se sostiene la polémica tradicional sobre el "realismo" o el "instrumentalismo". En la medida en que la capacidad expresiva de un vocabulario está

\footnotetext{
${ }^{18}$ Mientras que podemos definir de forma clara y precisa - mediante operaciones de substitución, por ejemplo- las nociones inferenciales, la relación de denotación permanece oscura, como algo que requiere una elucidación ulterior. Peregrin (1997) ha argumentado plausiblemente en este sentido.

${ }^{19}$ Por otra parte, la perspectiva recién expuesta abre la posibilidad, que aquí sólo puede quedar sugerida, de contemplar los propios vínculos modelo-teóricos como un modo de representar relaciones pragmáticas constitutivas de contenido, cuando los conceptos vinculados se insertan en teorías que cumplen determinados requisitos estructurales.
} 
restringida y posibilitada por las prácticas que le confieren significado a sus elementos, su ontosemántica u ontología es relativa en algún sentido a tales prácticas. Pero se trata de relatividad inocua, que no implica la contingencia o la arbitrariedad de sus construcciones -teorías-, una vez que se asume que ningún vocabulario está exento de la misma. Una característica central a la línea de pensamiento pragmatista es su crítica a la noción de un punto de vista absoluto, el "punto de vista del ojo de Dios”. Cualquier esfuerzo cognoscitivo está ligado a intereses y prácticas, lo que no quiere decir que no podamos evaluar la adecuación de dichos esfuerzos a tenor de los recursos que la participación en tales prácticas pone a nuestra disposición. Si asumimos que los recursos de la ciencia extienden, mejoran y corrigen los del "sentido común", podremos juzgar que sus resultados merecen mayor crédito ontológico que los de éste.

El modo que he propuesto de entender las relaciones del "sentido común" con la ciencia logra acomodar a la vez dos intuiciones: primero, que la ciencia puede corregir aspectos del "sentido común" -lo cual se antojaría difícil si tales relaciones fuesen directamente semánticas o empíricas- y, segundo, que el "sentido común" está "a la base" (pragmática) del conocimiento científico. ${ }^{20}$

\section{Una experiencia sin "base"}

Hasta ahora he pospuesto la discusión de un malentendido que atraviesa el debate acerca del contenido empírico de las teorías científicas. Este malentendido asume la siguiente forma: si las teorías científicas han de hablar sobre el mundo, deben mantener conexiones semánticas con conceptos que se caractericen por ostentar una relación privilegiada con la experiencia observable. En esta sección quisiera cuestionar esta doctrina y aportar elementos para una explicación alternativa del papel de la experiencia o la observación en nuestros conceptos y teorías científicas.

A mi modo de ver, detrás de este malentendido se encuentra un dogma de raíz empirista: la cadena de constitución o determinación de significado es la misma que acredita o ilustra la solvencia epistemológica de los conceptos que se encuentran al final de la cadena, a partir de los conceptos que se encuentran a su base y están en contacto directo con la experiencia. Es decir, la relación de constitución de significado va paralela a la relación de justificación empírica. ${ }^{21}$ De este dogma se desprende que a la base (de constitución) semántica de nuestros sistemas conceptuales -incluidas las teorías científicas-, si éstos han de hablar del mundo, deben encontrarse conceptos en abierta relación con la experiencia, conceptos puramente observacionales. Como dentro del estructuralismo la distinción 'T-teórico/T-no teórico' ( $T /$ no-T) y la consiguiente noción de 'vínculo inter-teórico' se utilizan para elucidar la constitución semántica de los conceptos de las teorías científicas, podríamos vernos tentados a asumir que las cadenas de teorización inducidas por el establecimiento de vínculos interpretativos desempeñan ese doble papel -semántico y epistemológico- señalado por el dogma empirista. Así pues, si nuestras teorías científicas son también empíricas, a la base de la cadena debe encontrarse un conjunto de conceptos observacionales por los que la experiencia y con ella el contenido empírico ingresa en la constitución del significado de los conceptos científicos de las sucesivas teorías.

Sin embargo, la metateoría estructuralista debería sustraerse a esta compulsión empirista, precisamente a tenor de los dos principios centrales sobre los que descansa la mencionada distinción y el recurso a vínculos inter-teóricos y que, según expuse en la sección 1, el estructuralismo hace suyos: el holismo local y el criterio de T-teoricidad relativizado a las teorías. El holismo local excluye, primero, que la constitución de significado se conciba como un proceso de transmisión lineal de teoría a teoría

\footnotetext{
${ }^{20}$ Es en este sentido en el que la propuesta que sugiero es pragmatista, en la medida en que subraya las condiciones prácticas de acceso a las teorías como constitutivas del contenido de los conceptos en ellas implicados y por lo tanto como determinantes de sus ámbitos de referencia. Una verdadera pragmática de las teorías científicas no puede, entonces, consistir en una lista de contingencias que penden sobre la aplicación concreta de términos o conceptos cuyo significado está ya determinado de manera previa, como parece desprenderse del trabajo de Moulines (2002).

${ }^{21}$ Por supuesto, ésta es otra manera de presentar el "segundo dogma del empirismo" criticado por Quine (1953, p. 247), el reduccionismo, de acuerdo con el cual "todo enunciado que tenga sentido es equivalente a alguna construcción lógica basada en términos que se refieren a la experiencia inmediata”. No obstante, no me comprometeré con esta formulación, que creo más específica.
} 
-sugerido por la metáfora de la "cadena"-, donde cada una sólo aporta "recursos de cálculo" con respecto a la anterior, y, segundo, que puedan existir conceptos que obtengan su significado directa y exclusivamente de su relación con la experiencia, algo así como conceptos puramente observacionales. Articulado con el holismo local, el criterio estructuralista de T-teoricidad circunscribe el alcance de la determinación de significado de una teoría $T$ por parte de otra(s) teorías a sólo una parte de la primera, la correspondiente a sus modelos parciales -o modelos de datos-, a la que se denomina 'contenido empírico' de T. En este sentido técnico, el 'contenido empírico' de T procede de otra(s) teoría(s), no de la experiencia, ni de ningún repertorio específico de conceptos observacionales. No hay por qué aspirar a que esta remisión a otras teorías deba tener un final en alguna base permanente, como traté de mostrar en la sección 3.2. Ello debería excluir la búsqueda de una fuente absoluta del contenido empírico con independencia de las teorías que estemos considerando, y por lo tanto la búsqueda de una base final de conceptos de los que procediera en última instancia todo contenido empírico. ${ }^{22}$ No deberíamos tratar de encajar a la fuerza en la caracterización que ofrece el estructuralismo distinciones que, como la que opone 'teórico' a 'observacional' en términos absolutos, corresponden a enfoques completamente diferentes sobre el conocimiento científico.

No obstante lo anterior, es legítimo plantearse algunas cuestiones que subyacen a las tentativas empiristas. La ontosemántica de las teorías científicas queda en suspenso mientras no se explique de algún modo la relación entre las teorías y la experiencia. En primer lugar, asumiré que no son las teorías mismas las que se relacionan con la experiencia, sino los defensores de la teoría -los que se comprometen con ella-, por medio de sus interacciones con el mundo en tanto que usuarios de la teoría y sus conceptos. De acuerdo con un enfoque pragmatista, ésta es una característica general de nuestros conceptos, que no denotan mágicamente determinados sectores del mundo, al margen del modo en que los usamos, en combinación con nuestras capacidades de discriminación y otros recursos expresivos.

Así pues, para elucidar qué papel juega la experiencia observacional en nuestras prácticas epistemológicas, por ejemplo en la aplicación de nuestras teorías, tenemos que acudir a modos de usar los conceptos, más que a su constitución intrínseca. Entre esos usos, algunos pueden catalogarse como observacionales, a saber, los que se llevan a cabo en el seno de lo que se viene llamando 'enunciados de observación'. Es por medio de tales usos como adquiere contenido empírico nuestra actividad conceptual. En la concepción inferencialista, este punto se recoge expresamente al diferenciar desde el comienzo entre usos específicamente inferenciales y usos no-inferenciales ${ }^{23}$ de los conceptos. Con esta consideración no hago más que insistir en algo que desde los comienzos de la metateoría estructuralista debería haber quedado claro: la distinción ' $T / n$ no- $T$ ' no se corresponde con la clásica dicotomía 'noobservacional/observacional'. O dicho de otro modo, la distinción entre uso observacional (en un enunciado observacional) y uso no-observacional es transversal a la distinción 'no- $T / T$ ', y responde por tanto a otros criterios.

\subsection{Enunciados de observación}

Defenderé que los criterios distintivos de los enunciados de observación son de naturaleza pragmática. En particular, un enunciado de observación es aquél que se profiere (en rigor, habría que decir: cuya proferencia puede justificarse) como respuesta a una situación experiencial. Ello significa que atendiendo exclusivamente al contenido semántico no podemos distinguir un enunciado observacional de otro que no lo sea. Un hablante puede estar acreditado para adquirir un compromiso con una oración $\mathrm{O}$ de dos modos diferentes: o bien porque está acreditado para suscribir un conjunto $O_{1}, \ldots, \mathrm{O}_{n}$ $(n \geq 1)$ de oraciones (mejor dicho, compromisos doxásticos) que a su vez le acreditan para suscribir $\mathrm{O}$, o

\footnotetext{
${ }^{22}$ En realidad, esa búsqueda de puntos de contacto con la experiencia resulta más afín a una imagen instrumentalista de las teorías científicas, de acuerdo con la cual sólo los conceptos conectados con la experiencia cuentan con credenciales suficientes como para comprometernos con la existencia de sus supuestos referentes.

${ }^{23} \mathrm{O}$ inferenciales en un sentido atenuado, si se entiende que éstos comportan un "movimiento inferencial" que tiene por origen (en el caso de informes de observación) o destino (e el caso de reglas prácticas de acción) situaciones extra-lingüísticas. Recuérdese la clasificación de tres tipos de movimientos inferenciales que introduje durante mi presentación del inferencialismo semántico en la sección 2.2.
} 
bien porque se encuentra en presencia de una situación observacional $S$ que cuenta como condición suficiente para suscribir $\mathrm{O}$ y frente a la que posee capacidades discriminatorias fiables. En términos llanos, podemos llegar a $\mathrm{O}$, o bien mediante una inferencia basada en $\mathrm{O}_{1}, \ldots, \mathrm{O}_{n}$, o bien a partir de la observación de S. Sólo en el segundo caso, la proferencia de $\mathrm{O}$ se considerará un enunciado de observación. Nótese que en ambos casos, el contenido semántico de $\mathrm{O}$ será el mismo, por lo tanto, éste no puede servir para distinguir los enunciados observacionales -salvo para descartar de antemano como posibles observacionales oraciones cuyo valor de verdad sea siempre el mismo con independencia del contexto de proferencia, es decir, las llamadas 'oraciones eternas'-.

A título de ejemplo, supongamos que nuestra $\mathrm{O}$ expresa lo siguiente: "La vara de la derecha es más larga que la vara de la izquierda". Hay dos tipos de condiciones bajo la cuales podemos estar justificados para aceptar O: primero, si estamos justificados para aseverar, por ejemplo, "La vara de la izquierda es más corta que la de la derecha"; segundo, si presenciamos que la vara de la derecha es más larga que la de la izquierda. El primer modo únicamente involucra el ejercicio de las capacidades inferenciales asociadas a nuestra competencia de uso de los conceptos implicados. El segundo añade a éstas otras capacidades discriminatorias por las que podemos responder de manera fiable y diferenciada a rasgos del entorno. Aunque la relación de $\mathrm{O}$ con situaciones concretas a las que somos sensibles y que constituyen condiciones suficientes no-inferenciales de aserción puede ser esencial al contenido de O, ello será así tanto en su uso inferencial como en su uso no-inferencial (observacional); lo único que ello nos dirá es que $\mathrm{O}$ puede ser usada como enunciado de observación. Por tanto, una consideración del contenido de $\mathrm{O}$, por amplia que sea, no arrojará dictamen alguno sobre el carácter observacional de su proferencia en casos concretos.

Quine desarrolló en sus últimos años una concepción de los enunciados observacionales en esta línea pragmatista, aunque desprovista de los elementos inferencialistas que, inspirándome en Brandom (1994, especialmente el capítulo 4), he incorporado en la presentación anterior. Para Quine (1990, p. 20), "una oración observacional es una oración ocasional que suscita el acuerdo inmediato de los hablantes de una lengua cuando éstos son testigos de la situación correspondiente". Cuatro son, según Quine, las características de este tipo de oraciones. La primera es su carácter ocasional. El valor de verdad de una oración ocasional varía en función de lo que ocurra en el mundo: en ocasiones es verdadera y en ocasiones, falsa. Ello sugiere cuál es la segunda característica: cada oración de observación ha de estar asociada afirmativamente con una gama de estímulos del sujeto y negativamente, con otra. En esto piensa Quine cuando habla de "situación correspondiente". Por 'gama de estímulos' (afirmativa o negativa) se entiende el conjunto de estímulos asociados (positiva o negativamente) a una oración de observación. La tercera exigencia es que la oración de observación tiene que provocar el asentimiento o el disentimiento inmediato del sujeto cada vez que se dé un estímulo pertinente. Un cuarto requisito es la intersubjetividad: una oración de observación ha de concitar el acuerdo, en uno u otro sentido, de todos los hablantes competentes que presencien la misma situación. La intersubjetividad garantiza la objetividad. Nótese, por otra parte, que, así descrita la exigencia de intersubjetividad, las oraciones de observación quedan relativizadas a comunidades particulares de habla.

En realidad, con lo anterior no queda precisado criterio alguno para determinar si una oración dada está siendo usada en un contexto particular como observacional. Lo que Quine define es el conjunto de oraciones potencialmente observacionales. Con esta salvedad -que, con todo, creo de importancia-, y a expensas de discutir más adelante un aspecto de la explicación quineana del que discrepo, de momento puede servirnos. De ella se sigue que tanto "Llueve" o "La vara de la derecha es más larga que la de la izquierda" como "Por ahí va un hipotiroideo" pueden funcionar como enunciados de observación. Es decir, la definición de 'oración observacional' nada dice acerca de la teoría encerrada en tales oraciones, que no se caracterizan por generarse a partir de un repertorio de conceptos observacionales, opuesto a otro de conceptos teóricos. Así pues, puesto que los conceptos de las teorías científicas pueden intervenir en oraciones potencialmente observacionales, éstas permiten conectar una teoría dada con situaciones experienciales a fin de contrastarla. 
Ahora bien, ¿cómo compaginar estas consideraciones con la metateoría estructuralista? Con otras palabras, ¿cómo se relacionan los enunciados de observación con las teorías científicas? Se asume que, al margen de su aparato puramente formal o teórico, la conexión de las teorías con la experiencia tiene lugar a través de sus aplicaciones pretendidas. Es en virtud de sus aplicaciones pretendidas como las teorías científicas adquieren contenido empírico. Y también es en este punto donde intervienen los enunciados de observación. Las aplicaciones pretendidas están incluidas en el conjunto de modelos parciales de la teoría y, por tanto, el contenido de los conceptos en términos de los cuales se especifiquen tales aplicaciones procederá generalmente de teorías anteriores. Pero las caracterizaciones concretas de situaciones del mundo como aplicaciones pretendidas de la teoría se realizarán mediante enunciados en los que se empleen esos conceptos y cuya aserción se encuentre acreditada en tales circunstancias. Estos enunciados son los enunciados observacionales o los informes no-inferenciales que venimos considerando. Los enunciados observacionales desempeñan un primer papel en la obtención de modelos de datos para una teoría en situaciones experienciales concretas.

Para ejemplificar este punto, me remitiré a la explicación esquemática que ofrece Moulines (2012) de la determinación de modelos de datos a partir de situaciones experienciales tomadas, por decirlo así, "en bruto". El proceso comienza con (1) una situación experiencial $\left(S E_{p}\right)$, presenciada por un individuo $P$ mientras contempla el cielo nocturno. (2) En el curso de diversas interacciones de $P$ con otros individuos que presumiblemente forman parte de la misma comunidad de habla GC -la llamo así porque es como Moulines la designa, jugando con la kuhniana "generación científica"-, se adoptan algunas decisiones. ${ }^{24}$ Éstas conciernen al uso de determinados procedimientos de registro, selección y medición. En este estadio, la original $S E_{p}$ ha pasado a ser una situación experiencial intersubjetivamente controlada $S_{E I C}$. Una vez fijada ésta, (3) se procede a la construcción de una "representación" que ya puede ser considerada como un modelo de datos para $S E I C_{p}$, o $M D_{p}$. Escribe Moulines (2012):

Esta representación se ha construido de acuerdo a una serie de enunciados o "axiomas":

$\left(A_{1}\right)$ Punto $p_{1}$ sobre el papel cuando la arena cubre la marca $m$ representa Mercurio.

$\left(A_{2}\right)$ Punto $p_{2}$ sobre el papel cuando la arena cubre la marca $m$ representa Venus.

$\vdots$

$\left(A_{m}\right)$ Punto $p_{m}$ cuando la arena cubre la marca $m^{\prime}$ representa Mercurio.

$\left(A_{n}\right)$ Distancia de $p_{1}$ al centro cuando la arena cubre la marca $m$ es $r_{1}$.

$\left(A_{n+1}\right)$ Distancia de $p_{2}$ al centro cuando la arena cubre la marca $m$ es $r_{2}$.

$\vdots$

Después de [...] lo que los sociólogos de la ciencia llaman "negociaciones" [...], GC acuerda convalidar los "axiomas" $\left(A_{1}\right),\left(A_{2}\right), \ldots,\left(A_{m}\right), \ldots,\left(A_{n}\right),\left(A_{n+1}\right), \ldots$ Este proceso de convalidación se lleva a cabo en parte por convención (por ejemplo, para $\left.\left(A_{1}\right),\left(A_{2}\right), \ldots\right)$, en parte por medio de procedimientos estandarizados y refrendados por GC (por ejemplo, contando de cierta manera el número de casillas sobre el papel cuadriculado que separan cada $p_{i}$ del centro de coordenadas para $\left.\left(A_{n}\right),\left(A_{n+1}\right), \ldots\right)$. Una vez concluido este proceso de convalidación, GC declara verdaderos los enunciados $\left(A_{1}\right),\left(A_{2}\right), \ldots,\left(A_{n+1}\right), \ldots$ (Moulines 2012, pp. 25-26)

La conceptualización desplegada en estos enunciados o axiomas coincide con la que sirve para caracterizar la estructura de $M D_{p}$, presentada por Moulines como el siguiente tuplo: $\left\langle\left\{p_{1}, \ldots, p_{5}\right\},\left\{\ldots m_{i} \ldots\right\}\right.$, $d\rangle$, "donde $d$ es una función diádica constituida por los triplos $\left\langle p_{i}, m_{i}, r_{i}\right\rangle$ (con $r_{i} \in Q$ ) de aquellos

\footnotetext{
${ }^{24}$ En otra parte del mismo texto, Moulines (2012) precisa que el resultado de estas interacciones es la obtención de una "base operacional" para la $S E$ inicial:
}

El problema de entrada [...] es que la identidad de cada SE es, a fines científicos, demasiado confusa y vacilante. Hay que acotarla mejor de lo que suele hacerse en la vida cotidiana. Para ello, el científico procede a una serie de acciones e interacciones intersubjetivas, basadas principalmente en la comunicación lingüística con sus "pares", la observación sistemática y/o las manipulaciones de objetos de mediano tamaño. Así se construye, en un primer paso, lo que podemos llamar una "base operacional", BO, para SE, con lo cual la SE de partida al final se convierte y codifica en una situación experiencial intersubjetivamente controlada (SEIC). La misma, o análoga, BO puede servir para construir otras SEICs. (Moulines 2012, p. 24) 
parámetros que se corresponden en cada uno de los enunciados $\left(A_{n+j}\right), j \geq 0$ " (Moulines 2012, p. 26). Y añade: "Del proceso de convalidación arriba descrito se desprende que $M D_{p}$ es un modelo de $\left(A_{1}\right), \ldots$, $\left(A_{n}\right), \ldots$... (Moulines 2012, p. 26).

Pues bien, al menos los axiomas $\left(A_{i}\right), i \geq n$, de esta lista constituyen enunciados de observación; ellos habilitan la subsunción de situaciones experienciales concretas bajo estructuras conceptuales que permiten contemplarlas como modelos parciales, en cuyos términos llevar a cabo contrastaciones empíricas. Es decir, la transición entre situaciones del tipo $S E I C_{p}$ y modelos del tipo $M D_{p}$ se opera mediante enunciados de observación -junto con 'axiomas de interpretación' convencionales, en este caso, $\left(A_{1}\right)-\left(A_{m}\right)$-. Nótese que los conceptos empleados en los axiomas pueden ser T-teóricos para alguna teoría T, sin menoscabo de lo que Moulines llama su "convalidación", de su carácter de enunciados observacionales. La transición de (1) a (2) garantiza la intersubjetividad de tales enunciados, en la medida en que la obtención de una SEIC $p$ presupone que los miembros de GC forman parte de la misma comunidad de habla (la de los usuarios de la teoría), esto es -como prefiero decir-, presupone la convergencia de sus capacidades expresivas.

Aunque éste es el lugar en el que eminentemente adquieren importancia los enunciados de observación, hay otros momentos de la práctica científica en que podemos imaginar que desempeñan una función inestimable, a saber, en cualquier situación en la que los practicantes de una teoría científica interaccionen con las situaciones concretas en la que pretenden aplicarla y con los medios de su aplicación. ${ }^{25}$ Por ejemplo, en la expresión de los resultados de mediciones y otros procedimientos de determinación, por muy teóricos que sean los conceptos involucrados, se requerirá el ejercicio de disposiciones fiables de respuesta discriminatoria que se expresarán en forma de enunciados de observación. En todos estos casos de interacción fiable, se infiltra la experiencia como fricción efectiva que constriñe la aplicación de los conceptos, con independencia de la constitución teórica de éstos.

De hecho, para que ciertos enunciados puedan servir de la manera indicada para la obtención de modelos de datos a partir de situaciones perceptivas, los conceptos expresados en tales enunciados -y que supuestamente proceden de teorías subyacentes a aquélla para la que se obtienen los modeloshan de contar con un uso observacional previo. La posibilidad de desempeñar dicho papel debe descansar en un rasgo de su contenido, que probablemente se manifieste ya en la teoría previa, donde el concepto en cuestión sea T-teórico. Ello puede ocurrir en la expresión -mediante enunciados observacionales- de los resultados de procedimientos por los que se determine la aplicación del concepto -en conjunción con otros- a sistemas concretos (o, si el concepto es cuantitativo, su valor para dichos sistemas). En este caso, el uso observacional del concepto presupone la aplicabilidad de la teoría donde se introduce como T-teórico. Es decir, no se puede aplicar tal concepto a sistemas reales sin asumir que éstos son modelos efectivos de la teoría. Recuérdese que una característica central que Zamora Bonilla (2003) asignaba a los "conceptos observacionales" era que su empleo no-inferencial implica un compromiso (inferencial) con las restricciones efectivas de la teoría. Vemos ahora que no necesitamos invocar supuestas "teorías básicas" para asimilar esta circunstancia; podemos dar cuenta del empleo observacional de conceptos T-teóricos en el seno de teorías "normales", y sin que se derive la consecuencia ciertamente anómala de que los modelos parciales de una teoría coincidan con sus modelos actuales -es decir, que su contenido empírico y su contenido teórico sean indiscernibles-, como ocurre con las citadas "teorías básicas observacionales".

Aunque el ejemplo de Moulines (2012) está deliberadamente simplificado, de modo que los conceptos expresados en los axiomas $\left(A_{n+1}\right)$ no remiten expresamente a ninguna teoría previamente disponible, en los casos reales, las nociones empleadas para indicar, digamos, la distancia o el tiempo transcurrido consistirán en conceptos procedentes de otra(s) teoría(s) cuya validez está presupuesta en la convalidación de los enunciados equivalentes a $\left(A_{n+1}\right)$, si es que éstos han de valer como modelos de datos equiparables a $M D_{p}$. En una situación real, si las $p_{i}$ y los $m_{j}$-que aparecen en $\left(A_{n+1}\right)$ - han de expresar el tipo de conceptos susceptibles de integrar los modelos de datos de la teoría considerada, no representarán simplemente una cantidad de cuadrados en un papel ni marcas en dos conos opuestos

\footnotetext{
${ }^{25}$ Por ejemplo, durante las interacciones en el curso de las cuales se decanta una 'base operacional' BO para SE; véase la nota anterior.
} 
llenos de arena, sino el espacio real y el tiempo real transcurrido; de lo contrario, los modelos de datos de la teoría no vendrían dados por relaciones entre cuerpos celestes, sino por inscripciones en papeles y objetos más o menos cilíndricos. So pena de arbitrariedad, la aceptación de dichos enunciados $\left(A_{n+1}\right)$ ha de basarse en el contenido que dichos conceptos poseen ya en las mencionadas teorías anteriores. Una parte de este contenido debe guardar, por tanto, alguna relación con el ejercicio de capacidades fiables de discriminación perceptiva por parte de quienes los emplean, ya en las teorías subyacentes, ejercicio que se concreta en la educción de enunciados observacionales formados por dichos conceptos. Es decir, la posibilidad de usar los conceptos en cuestión en enunciados observacionales debe formar parte de la constitución de su contenido de manera integrada con aquellos rasgos que determinan las referencias asociadas a los conceptos correspondientes. Y es en relación con este punto donde la explicación inferencialista del contenido ofrece a mi parecer mejores perspectivas que la suministrada por Quine.

\subsection{Una enmienda inferencialista}

La cuestión de fondo concierne a la relación que el contenido de los conceptos involucrados en los enunciados de observación debe mantener con situaciones experienciales a fin de que dichos enunciados puedan servir para determinar las estructuras parciales en los que esos conceptos aparecen. Por un lado, la vinculación de los enunciados de observación con las situaciones que se consideran acreditativas parece ser causal; por el otro, la conexión de los conceptos implicados en tales enunciados con la teoría (a través de los modelos) es lógico-semántica. Los conceptos empleados en los enunciados de observación deben ser los mismos que constituyen las estructuras de la teoría, para que aquéllos sirvan como fuente de evidencia en la construcción de éstos. ¿Cómo se asegura esa identidad?

Al especificar el significado de los enunciados de observación únicamente mediante su asociación con gamas de estímulos - de acuerdo con la segunda característica que les atribuye-, Quine deja por aclarar cómo se seleccionan referencias concretas dentro de la cadena de sucesos causante de la estimulación. Los enunciados de observación se individúan, según Quine, en términos exclusivamente proximales. Dos oraciones de observación tienen el mismo significado para un hablante cuando llevan aparejadas las mismas gamas de estímulos. La estimulación es el suceso más próximo (o proximal) al sujeto epistémico, dentro de la cadena co-variante de sucesos que supuestamente causa la educción del enunciado de observación. Las gamas de estímulos se localizan en los receptores sensoriales del sujeto que se enfrenta a la situación estimulativa. Es la peculiar configuración de éstos en cada hablante la que determinan el significado para ese hablante de una oración observacional dada. Puede verse ahora cuál es el problema: ¿cómo puede entonces esa oración mantener relaciones (lógico-semánticas) con otras oraciones, en virtud del significado de sus términos? Esto es, ¿cómo puede una oración observacional servir para respaldar, confirmar, refutar, etc. una o varias oraciones, diferentes pero emparentadas con aquélla en razón de la comunidad de algunos de sus términos? La concepción proximal del significado de las oraciones observacionales parece entrar en conflicto con la reclamada intersubjetividad que debe caracterizarlas. Pero es la concepción que expresamente adopta Quine, quien relega la cuestión de la intersubjetividad a "aspectos externos de la comunicación" (1990, p. 72), más que a la determinación semántica o evidencial de las propias oraciones.

El problema sigue siendo la determinación de la referencia distal de la estimulación, es decir, los objetos y sucesos de los que tratan nuestros enunciados observacionales. Los términos contenidos en enunciados observacionales han de poder aparecer con la misma referencia en otros enunciados, a fin de que aquéllos puedan ofrecer apoyo evidencial a éstos. Nuestra disposición natural de respuesta diferenciada ante los estímulos no discrimina por sí misma un elemento concreto dentro de la cadena causal global que culmina con la respuesta, y por tanto no selecciona significado alguno más allá del puramente proximal. Por lo que concierne exclusivamente a dicha disposición, ésta reacciona ante cualquier suceso de la cadena y ante ninguno de ellos en particular, y por lo tanto no basta para nuestros propósitos. 
Éste es, por cierto, el fundamento de la argumentación quineana a favor de la inescrutabilidad de la referencia y la relatividad ontológica. Nótese que este resultado obedece a que la única caracterización que desde un punto de vista evidencial Quine ofrece de los enunciados observacionales es su asociación con gamas de estímulos. Ante una misma gama de estímulos pueden aducirse distintas acotaciones referenciales. El propio Quine pretende mitigar los inconvenientes epistemológicos de esta línea de argumentación mediante su doctrina del doble aspecto -holofrástico y analítico- de los enunciados de observación. En virtud de su aspecto holofrástico, los enunciados de observación constituyen fuentes evidenciales instantáneas, sólidas y fiables: es este aspecto el que garantiza la conexión con el mundo de tales oraciones, consideradas como respuestas unitarias, establecidas por condicionamiento, a situaciones estimulativas. Ahora bien, tales enunciados pueden servir para contrastar teorías en virtud de su carácter analítico, en el que cobra relevancia la articulación del enunciado a partir de palabras que aparecen en otros enunciados (de la teoría). Sólo en este plano analítico los enunciados poseen carga semántica y ontológica; en el nivel holofrástico, el hablante no se compromete con contenido ontológico alguno, sino tan solo con la presencia de una determinada gama de estímulos. ${ }^{26}$

A mi juicio, esta doctrina de la doble naturaleza o aspecto de los enunciados de observación no logra explicar de un modo congruente -no ad hoc- cómo se integran ambos ingredientes o dimensiones, heterogéneas en principio, de significado. La validación de un enunciado de observación no es puramente "holofrástica", sino que entraña desde el principio consecuencias que involucran a los aspectos ontosemánticos del lenguaje empleado. De lo contrario, la aserción de un enunciado observacional no proporcionaría respaldo evidencial a teoría alguna: lo único que podríamos acreditar sería la presencia de determinadas activaciones en nuestro sistema sensorial, sin contenido semántico determinado, y el salto a la teoría con vistas a su contrastación sería inviable. Recordemos las dificultades -bien conocidas desde los tiempos del positivismo lógico- relativas a la posibilidad de que puedan darse relaciones evidenciales, propiamente justificantes, entre elementos no-conceptuales y elementos conceptuales. El inferencialismo, en cambio, al considerar que el significado de cualquier oración puede especificarse como la combinación de sus condiciones suficientes de aserción y sus consecuencias necesarias de aserción, reúne en una misma noción las dos funciones que Quine pretende atribuir a las oraciones específicamente observacionales: la "holofrástica", en términos de condiciones estimulativas de introducción; la analítica, en términos de consecuencias de aplicación y, por tanto, de relaciones inferenciales con otras oraciones.

¿A qué elemento concreto de la cadena causal estamos respondiendo al adquirir un compromiso con determinado enunciado de observación? Veíamos que nuestra capacidad de discriminación se dispara ante la cadena causal en su totalidad -en realidad, ante su "eslabón" proximal-. Según el inferencialismo, qué suceso se discrimine fiablemente dentro de ella está determinado por el rol inferencial de los conceptos efectivamente educidos como constituyentes del enunciado de observación. Es ésta una manera específica de concretar una estrategia general que ha sido divulgada por Davidson para hacer frente a estas cuestiones. Según ésta, el modo de individualizar un elemento en una cadena causal es convirtiéndolo en punto de intersección entre dos cadenas, es decir, uniendo dos cadenas causales de modo tal que ambas converjan en un único elemento o suceso. Para señalar un punto en una línea se necesita hacerla intersecar con otra. Davidson ha defendido que este proceso opera como una triangulación a tres bandas, entre dos hablantes que interaccionan entre ellos y el mundo: determinadas situaciones en las que tales hablantes tratan de aplicar (conjuntamente) conceptos.

La triangulación encauza las disposiciones fiables de discriminación -en las que se basa la educción de enunciados observacionales- dentro de las interacciones normativas que confieren en general significado a nuestras prácticas lingüísticas. Con ello, se integra de manera expresa la diversidad de los puntos de vista -i.e., la intersubjetividad- de los hablantes en la determinación del contenido de los conceptos que éstos aplican a las situaciones con las que interactúan. Escribe Davidson (1997, p. 184):

${ }^{26}$ Ver, p.e., Quine (1990, p. 26s.). 
"La interacción social, la triangulación, nos proporciona también la única explicación de cómo la experiencia da un contenido específico a nuestros pensamientos”. Cierto es que Quine propone algo parecido a esta triangulación comunicativa, a fin de dar cuenta de la traducción y de la intersubjetividad. Pero, para Davidson, esa triangulación comunicativa no es un elemento adicional o externo a la determinación del significado, sino parte constitutiva de dicha determinación, por cuanto en ella se decide la referencia distal de nuestros enunciados observacionales (aquello que los causa). Esas interacciones normativas dotan de contenido semántico a las expresiones resultantes de dichas disposiciones compartidas, que se ejercen en el curso del aprendizaje del lenguaje y también en su uso cotidiano. De este modo, la intersubjetividad no necesita estipularse como requisito adicional para una clase específica de oraciones, sino que está presupuesta en la consideración misma de cualquier expresión como una oración del lenguaje, aunque esa expresión sea el resultado de ejercitar de manera automatizada una disposición natural de respuesta frente a estímulos.

El inferencialismo añade un plano más de triangulación: la que se da entre las funciones inferenciales de los conceptos involucrados. Podemos apelar a estas funciones inferenciales para individuar el contenido específico del enunciado de observación que estemos considerando. Según sean las conexiones inferenciales de un enunciado, éste se considerará como determinando referencias distintas, aunque las gama de estímulos permanezca constante. Tomando el conocido ejemplo quineano, Brandom (1994, p. 429) se pregunta por qué al decir "Gavagai" puede alguien considerarse comprometido con la presencia de un conejo, más que con una especie de moscas que invariablemente acompañan a los conejos (quizá como parásitos). La diferencia no radica en nuestras disposiciones de respuesta diferencial, que pueden permanecer constantes en ambos casos. "It lies rather in the inferential role of the response 'gavagai"” y continúa Brandom:

\begin{abstract}
For instance, does the commitment undertaken by that response include a commitment to the claim that what is reported can fly? Or is the claim expressed by 'gavagai' incompatible with the further characterization of the item reported as flying? If it is incompatible, then it is not the flies that are being reported. What determines which element of the causal chain of covarying events that reliably elicit the report is being reported is the inferential role of the report, what it entails, what is evidence for it, what it is incompatible with. (Brandom 1994, p. 429)
\end{abstract}

Una misma gama de estímulos puede asociarse a enunciados de significado diferente. Lo que marca dicha diferencia de significado es la distinta articulación inferencial de cada una de ellas. Como indiqué anteriormente, a fin de compaginar este planteamiento con los recursos estructuralistas de análisis, puede considerarse que dicha trama inferencial queda recogida en las características modeloteóricas de algunos de los conceptos involucrados en el enunciado de observación, los que pertenecen a teorías determinadas.

La constricción que el entorno, el mundo de los hechos, ejercen sobre nuestro sistema cognitivo tiene desde el comienzo un carácter conceptual. La apelación a "contenidos no-conceptuales" previos oscurece la explicación de este punto. Tampoco está claro qué clase de papel desempeñarían los "escenarios preceptúales", como un dominio puramente "externo" o pre-conceptual, a la hora de explicar el contenido empírico de los conceptos o la obtención de modelos de datos. No hay más criterios de identidad para los escenarios perceptuales que aquéllos que se derivan de las relaciones inferenciales entre conceptos involucrados en diferentes modelos de datos. Ello no implica ninguna clase de idealismo pernicioso, sino tan solo un rechazo del dualismo entre "esquema conceptual" y “contenido material”, eficazmente criticado por Davidson (1974). Nuestros conceptos están constituidos en relación (de triangulación) con el mundo, llegan a él y lo incorporan como fricción efectiva. No necesitamos distinguir un ámbito especial de relación con la realidad, algo "dado" que justifique nuestra aplicación de conceptos mientras eso mismo se escamotea al ámbito de lo conceptual. Con una expresiva imagen, Brandom habla de la "solidez" de nuestras prácticas discursivas.

Discursive practices incorporate actual things. They are solid-as one might say, corporeal: they involve actual bodies, including both our own and the others (animate and inanimate) we have practical and 
empirical dealings with. They must not be thought of as a hollow, waiting to be filled up by things; they are not thin and abstract, but as concrete as the practice of driving nails with a hammer. [...] According to such a construal of the practices, it is wrong to contrast discursive practice with a world of facts and things outside it, modeled on the contrast between words and the things they refer to. (Brandom 1994, p. 332)

La presencia de una red inferencial (o teórica) de fondo contribuye a determinar el contenido semántico de los conceptos empleados en una afirmación, pero no hace a ésta menos observacional. Cuál sea el término de la relación referencial, a qué logre referirme, dependerá de la trama inferencial de los conceptos que emplee. De aquí se sigue que en principio no hay una parte de la realidad más accesible que otra a nuestra actividad conceptual, no hay entidades más apropiadas para ser denotadas por nuestros conceptos. No hay entidades en sí mismas observables, frente a otras que no lo sean, ni tampoco, por lo tanto, conceptos más observacionales que otros. La observación, la experiencia, el contenido específicamente empírico, proviene de los informes no-inferenciales, que ocupan un papel determinado en la trama inferencial de la mayoría de los conceptos, y no del carácter "ostensivo" de un reducido número de ellos, del que pudieran excluirse los conceptos supuestamente más abstractos

Sin duda, nuestra posibilidad de referirnos a ciertas entidades en el curso de enunciados de observación está limitada por la sensibilidad de nuestras capacidades de respuesta diferenciada. Hay diferencias situacionales por debajo de nuestros umbrales naturales de discriminación. Sin embargo, podemos extender artificialmente tales umbrales mediante el recurso a aparatos o dispositivos. Para poder aceptar que mediante la aplicación de tales expedientes (aparatos) accedemos a las entidades a las que se refieren los términos de nuestras teorías tenemos que asumir los compromisos inferenciales que su uso (el de tales aparatos) comporta. En términos estructuralistas, podemos decir que para aceptar que los aparatos de detección (o medición) relativos a un término $t$ realmente detectan o miden ejemplares de $t$, tenemos que comprometernos con que tales aparatos son modelos adecuados -de la teoría a la que $t$ pertenece, si $t$ es T-teórico o de otra diferente, si es T-no-teórico-. Pero esta circunstancia no es exclusiva del empleo de aparatos: como hemos visto, para aceptar que con el uso de cualquier concepto podemos referirnos a la entidad determinada que supuestamente éste denota, hemos de asumir el conjunto de compromisos inferenciales asociados a su uso correcto.

El uso de aparatos en la ciencia no difiere tanto como podemos pensar del uso habitual de conceptos. Las teorías forman parte de la extensión de nuestras capacidades expresivas, en particular, de nuestra capacidad de referirnos de manera fiable a entidades que están literalmente fuera del alcance de nuestros conceptos ordinarios o de "sentido común". Podemos en efecto establecer un paralelismo entre aparatos de medición/detección y conceptos: si mis capacidades de discriminación son sensibles a referentes de un concepto $x$, entonces debo comprometerme con las inferencias constitutivas de $x$; si el aparato $x$ detecta referentes del término $t$, debo comprometerme con que $x$ es un modelo de la teoría pertinente. Tales prácticas expresivas pueden estar tan integradas como las del lenguaje corriente, al menos para cierta comunidad de habla. De nuevo, las características inferenciales del enunciado educido resultan esenciales en la individuación de las referencias de sus términos.

What makes it a mu-meson that a physicist is reporting rather than a the hooker vapour trail that also forms part of the reliably covarying chain of events culminating in the report is to be understood not in terms of the differential responsive dispositions but in terms of the inferential role of the claim being made. (Brandom 1994, p. 223)

Si tuviéramos que definir, por extensión, la observacionalidad de términos o conceptos, podríamos decir que $t$ es un término observacional syss contamos con algún procedimiento fiable para determinar, ante una situación perceptual, si $t$ se aplica o no a la situación (o bien, si $t$ es cuantitativo, diferencias en el valor de $t$ ) -presuponga o no dicho procedimiento la aplicabilidad de la teoría a la que $t$ pertenece, es decir, sea $t$ T-teórico o no, de acuerdo con el criterio estructuralista de T-teoricidad. Recuérdese que cualquier informe no inferencial, si ha de estar dotado de contenido semántico, presupone ciertos compromisos inferenciales, asociados al uso de los conceptos expresados en dicho informe. Cualquier enunciado observacional dotado de contenido presupone la aplicabilidad de 
alguna teoría, presupone que la situación (estructura, modelo de datos, o cualquiera que sea el plano de caracterización que elijamos) que hace verdadera al enunciado en cuestión es un modelo para alguna teoría.

\section{La neutralidad de la experiencia. A vueltas con la inconmensurabilidad}

Díez (2002) considera deseable que una teoría de individuación de los conceptos científicos muestre "a conceptual link between the testing of scientific propositions and a basis of neutral observational prescientific 'something" (2002, p. 16) ${ }^{27}$ Lo contrario comportaría incurrir en lo que él llama "relativismo 'empírico' radical" (2002, p. 16). Su nota 4 nos informa del contenido de esta tesis.

By 'radical empirical relativism' I mean the thesis that no part of our cognitive interaction with the world is at the same time (a) essential for the understanding of science/knowledge, and (b) human "neutral", not subject to rational disagreement between normal human beings (irrespective of other differences in-other parts of-belief systems). (Díez 2002, p. 43)

Me gustaría mostrar que esta tesis, tomada a la letra, no genera el tipo de relativismo pernicioso que Díez sugiere con relación al contenido empírico de nuestros conceptos científicos. Podemos, en efecto, a tenor de las consideraciones anteriores, admitir sin escándalo que ninguna parte o región en particular de nuestra interacción cognoscitiva con el mundo es responsable único del contenido empírico de nuestras teorías científicas, ni, por lo tanto, esencial para nuestra comprensión de la ciencia o el conocimiento. Dada esta manera de formular y entender la condición (a), deja de tener sentido la (b). Ahora habría que decir más bien lo siguiente: ninguna parte en particular de nuestra interacción cognoscitiva con el mundo es "neutral", en el sentido de no estar sujeta a desacuerdo racional entre seres humanos normales.

Una razón es que, como me parece que muestran otros argumentos bien conocidos de Davidson, ${ }^{28}$ en cualquier interpretación se pone en juego la totalidad del sistema conceptual, sin que haya un ámbito de creencias o conceptos privilegiados. Ciertamente, en las situaciones radicales, conferiremos un papel destacado a los enunciados que consideremos observacionales, pero de ese modo no se delimita un repertorio de oraciones o, menos aún, de conceptos "neutros" en el sentido de Díez. Lo cual no significa una entrega al relativismo: se asume que la interpretación (o el entendimiento) es posible, sin que sea necesario que haya una región puramente observacional y "neutra", al margen de toda controversia, para que dos puntos de vista o sistemas conceptuales converjan. Tampoco significa que no podamos remitirnos a elementos que resulten neutrales en cada caso de discrepancia, como ilustra la posibilidad de retroceder a teorías subyacentes en casos de inconmensurabilidad.

Como indiqué en su momento (sec. 1), resultaría poco plausible -incluso nos costaría darle sentido a semejante posibilidad- que en casos en los que reconocemos inconmensurabilidad no-trivial entre dos teorías no acabáramos encontrando mediante este procedimiento alguna base común a ambas. Pero debe quedar claro que con este "retroceso" no nos estamos acercando a teorías cada vez más básicas en un sentido empírica o epistemológicamente definitivo o a regiones más observacionales de nuestro sistema conceptual -menos alejadas de nuestra "experiencia directa"-, sino a ámbitos conceptuales más ampliamente compartidos, desde donde es posible por tanto el acuerdo acerca del

\footnotetext{
${ }^{27}$ Aquí sólo puedo sugerir que mediante la noción amplia de 'función inferencial' podrían integrarse los cinco componentes que Díez (2002) cree necesarios en cualquier propuesta de caracterización de los conceptos (científicos), a saber: (i) el nomológico-formal, (ii) el aplicativo, (iii) el observacional, (iv) el operacional y el (v) ancestral-profano (folk-ancestral). La individuación de (i) en términos inferenciales es inmediata: las restricciones nomológicas-formales pueden entenderse como reglas inferenciales que rigen la composición y el uso de los conceptos en cuestión. Ello no obsta para que tales relaciones se especifiquen a base de teoría de modelos. Hemos visto cómo podríamos dar cuenta de (iii) y (v). (ii) y (iv) aluden, respectivamente, a la vinculación de los conceptos de una teoría con las aplicaciones pretendidas de ésta y a los procedimientos de determinación de los conceptos tratados - en los que éstos se ponen en relación con aparatos (de laboratorio), conductas, procedimientos y procesos que ha de dominar todo aquél que pueda contar como poseedor de los conceptos en cuestión-. De nuevo, podemos invocar la noción amplia de inferencia, según la cual una inferencia puede tener por "premisa" situaciones del mundo y por conclusión intervenciones o acciones sobre el mundo, para dar cuenta en términos inferenciales de ambos componentes, cuyo carácter pragmático está por otra parte fuera de toda duda.

${ }^{28}$ Ver, especialmente, Davidson (1973).
} 
contenido de nuestros otros conceptos, en relación con los cuales surgió la discrepancia. Por decirlo en la jerga introducida en la sección 2.3, se trataría de retroceder a vocabularios independientes respecto de las teorías concernidas. En los casos extremos, podemos vernos justificados a utilizar el vocabulario no-característico o de "sentido común", como un modo de aproximarnos tentativamente a los ámbitos expresivos rivales desde un punto de vista relativamente neutro. Pero conviene insistir en esto: de la circunstancia de que las llamadas "teorías de sentido común" sean, como indica su nombre, más ampliamente compartidas no se sigue que se hallen más cerca de la "pura experiencia", o que sea por medio o a partir de ellas como adquiere contenido empírico el resto de nuestras construcciones teóricas. El retroceso hacia teorías determinantes en el caso de teorías inconmensurables tiene sentido en relación con la consecución del acuerdo y la comunicación entre teorías o sistemas conceptuales divergentes, pero no tiene que ver con el esclarecimiento de su "base empírica".

Cierto es que, en casos normales, podemos decir que una teoría $T$ subyacente a otra $T^{\prime}$ constituye la base empírica de ésta, en la medida en que proporciona los conceptos T'-no-teóricos con los que representar las aplicaciones pretendidas de $T^{\prime}$. T determina, a través de sus modelos reales $\mathrm{M}$, el valor de los conceptos que conforman las estructuras contenidas en el conjunto de los modelos parciales de $T^{\prime}$, a saber, $M_{p p}$ '. Y ésta es una cuestión semántica, y en todo caso metodológica. Pero no veo por qué eso tendría que conllevar para un enfoque estructuralista que $T^{\prime}$ se halla más alejada de la experiencia que $T$ en ningún sentido relevante desde un punto de vista epistemológico.

Estas consideraciones permiten recuperar y aclarar las inciertas observaciones del último Kuhn (1981) acerca de la interpretación, como posible vía de acceso a paradigmas considerados inconmensurables. Un intérprete se adiestra en el manejo práctico de la teoría que pretende elucidar. El lenguaje no-característico usado en las prácticas de aprendizaje y enseñanza, en la disposición de ejemplos y la elección de paradigmas de aplicación, en el tipo de conexiones que la teoría mantiene con técnicas preexistentes, etc.: todo ello permitiría determinar las condiciones de uso de los conceptos de las teorías y, por tanto, -en este orden- sus ámbitos de referencia. Este lenguaje (de "sentido común", ordinario, no-característico) no está "más cerca de la experiencia", sino más ampliamente compartido, y ello por razones pragmáticas. No hay "lenguajes" o "estructuras conceptuales" subyacentes que habiliten la interpretación o traducción entre teorías, sino un conjunto de prácticas subyacentes. A través del lecho conceptual implicado en ciertas prácticas -que podemos presumir que son comunes o están ampliamente extendidas- es como establecemos correlaciones entre dominios empíricos de dos teorías inconmensurables.

\section{Bibliografía}

Balzer, W., Moulines, C. U. y J. D. Sneed (1986), An Architectonic for Science - The Structuralist Program, Dordrecht: Reidel. (Versión castellana de Pablo Lorenzano: Una arquitectónica para la ciencia. El programa estructuralista, Bernal: Universidad Nacional de Quilmes, 2012.)

Brandom, R. B. (1994), Making It Explicit. Reasoning, Representing, and Discursive Commitment, Cambridge, MA: Harvard University Press.

Brandom, R. B. (2000a), Articulating Reasons. An Introduction to Inferentialism, Cambridge, MA: Harvard University Press.

Brandom, R. B. (2000b), "Vocabularies of Pragmatism: Synthesizing Naturalism and Historicism”, en Brandom, B. (ed.), Rorty and His Critics, Oxford: Blackwell, pp. 156-183.

Brandom, R. B. (2008), Between Saying and Doing: Towards an Analytic Pragmatism, Oxford: Oxford University Press.

Davidson, D. (1973), “Radical Interpretation”, Dialectica 27: 313-328. (Reimpreso en: Davidson (1984), pp. 125-139.)

Davidson, D. (1974), “On the Very Idea of a Conceptual Schema”, Proceedings and Addresses of the American Philosophical Association 47: 5-20. (Reimpreso en: Davidson (1984), pp. 183-214.) 
Davidson, D. (1984), Inquiries into Truth and Interpretation, Oxford: Clarendon Press.

Davidson, D. (1999) “The Emergency of Thought”, Erkenntnis 51: 7-17. (Publicado por primera vez en alemán: "Die Emergenz des Denkens”, en Saltzer, W. G., Einsenhardt, P., Kurth, D. y R. E. Zimmermann (eds.), Die Erfindung des Universums? Neue Überle-gungen zur philosophischen Kosmologie, Frankfurt a.M.: Insel Verlag, 1997, pp. 152-167. Reimpreso en: Davidson, D., Subjective, Intersubjective, Objective, Oxford: Clarendon Press, pp. 123-134. Versión castellana de Olga Fernández Prat: "La aparición del pensamiento", en Davidson, D., Subjetivo, intersubjetivo, objetivo, Madrid: Cátedra, 2003, pp. 176-190.)

Díez, J. A. (2002), “A Program for the Individuation of Scientific Concepts”, Synthese 130: 13-48.

Díez, J. A. y P. Lorenzano (eds.) (2002), Desarrollos actuales de la metateoría estructuralista: problemas y discusiones, Buenos Aires: Universidad Nacional de Quilmes.

Falguera, J. L. (1999), “Ontosemantic Divergence and Comparability of Theories”, Logica Trianguli 3: 33-53.

Falguera, J. L. (2012), “De lo que tratan en común teorías inconmensurables”, en Peris-Viñé (2012), pp. 448-468.

Kuhn, T. S. (1962), The Structure of Scientific Revolutions, Chicago: University of Chicago Press, 2a ed., 1970. (Versión castellana: La estructura de las revoluciones científicas, México: FCE, 1975.)

Kuhn, T. S. (1976), "Theory-Change as Structure-Change: Comments on the Sneed Formalism”, Erkenntnis 10(2): 179 199. (Versión castellana: "El cambio de teoría como cambio de estructura", Teorema 7(2) (1977): 141-165.)

Kuhn, T. S. (1983), “Commensurability, Comparability, Communicability”, en Asquith, P. D. y T. Nickles (eds.) (1983), PSA 1982, vol. 2, East Leasing, Michigan: Philosophy of Science Association, pp. 669-688. (Versión castellana: "Commensurabilidad, comparabilidad y comunicabilidad", en Kuhn (2002), pp. 47-75.)

Kuhn, T. S. (1991), “The Road since Structure”, en Fine, A., Forbes, M. y L. Wessels (eds.) (1991), PSA 1990, vol. 2, East Leasing, Michigan, Philosophy of Science Association, pp. 3-13. (Versión castellana: "El camino desde La estructura", en Kuhn (2002), pp. 113-129.)

Kuhn, T. S. (2002), El camino desde la estructura, Barcelona: Paidós.

McDonough, J. K. (2003), "A Rosa Multiflora by Any Other Name: Taxonomic Incommensurability and Scientific Kinds”, Synthese 136: 337-358.

Moulines, C. U. (1987), "Referencia de términos científicos e inconmensurabilidad”, en Acero, J. J. y T. Calvo (eds.), Symposium Quine, Granada: Universidad de Granada, pp. 85-103.

Moulines, C. U. (1991), Pluralidad y recursión: Estudios epistemológicos, Madrid: Alianza.

Moulines, C. U. (1998), “Esbozo de ontoepistemosemántica”, Theoria 13(1): 141-159.

Moulines, C. U. (2002), “Dónde se agazapa la pragmática en la representación estructural de las teorías?”, en Díez \& Lorenzano (2002), pp. 99-115.

Moulines, C. U. (2012), “Ontoepistemosemántica en perspectiva estructuralista”, en Peris-Viñé (2012), pp. 19-31.

Peregrin, J. (1997), “Language and Its Models: Is Model Theory a Theory of Semantics?”, Nordic Journal of Philosophical Logic 2(1): 1-23.

Peris-Viñé, L. M. (ed.) (2012), Metateoría estructural: Filosofía de la ciencia en Iberoamérica, Granada: Universidad de Granada.

Quine, W. V. O. (1953), “Two Dogmas of Empiricism”, en Quine, W.V.O., From a Logical Point of View, Cambridge, MA: Harvard University Press, pp. 20-46. (Versión castellana de Manuel Sacristán: "Dos dogmas del empirismo”, en Valdés, L.M. (ed.), La búsqueda del significado, Madrid: Tecnos, $3^{\text {a }}$ ed., 1999, pp. 220-243.)

Quine, W. V. O. (1990), Pursuit of Truth, Cambridge, Mass.: Harvard University Press. (Versión castellana de Javier Rodríguez Alcázar, a partir de la $2^{\text {a }}$ ed. revisada del original: La búsqueda de la verdad, Barcelona: Crítica, 1992.)

Zamora Bonilla, J. P. (2003), "Meaning and Testability in the Structuralist Theory of Science”, Erkenntnis 59: 47-76. 